\title{
Masonry Dome Behavior under Gravity Loads Based on the Support Condition by Considering Variable Curves and Thicknesses
}

\author{
Asem Sharbaf ${ }^{1}$ (D), Mohammadreza Bemanian ${ }^{1, *}$, Khosro Daneshjoo ${ }^{1}$ and Hamzeh Shakib ${ }^{2}$ \\ 1 Department of Architecture, Tarbiat Modares University, Tehran 14115-111, Iran; \\ asem.sharbaf@modares.ac.ir (A.S.); khdaneshjoo@modares.ac.ir (K.D.) \\ 2 Department of Civil and Environmental Engineering, Tarbiat Modares University, Tehran 14115-111, Iran; \\ Shakib@modares.ac.ir \\ * Correspondence: bemanian@modares.ac.ir; Tel.: +98-912-108-1534; Fax: +98-218-800-8090
}

\section{check for} updates

Citation: Sharbaf, A.; Bemanian, M.; Daneshjoo, K.; Shakib, H. Masonry Dome Behavior under Gravity Loads Based on the Support Condition by Considering Variable Curves and Thicknesses. Buildings 2021, 11, 241. https://doi.org/10.3390/ buildings11060241

Academic Editors: Fernando F.

S. Pinho, Humberto Varum, Elena Ferretti and Giovanni Minafò

Received: 27 March 2021

Accepted: 7 May 2021

Published: 4 June 2021

Publisher's Note: MDPI stays neutral with regard to jurisdictional claims in published maps and institutional affiliations.

Copyright: (c) 2021 by the authors. Licensee MDPI, Basel, Switzerland. This article is an open access article distributed under the terms and conditions of the Creative Commons Attribution (CC BY) license (https:/ / creativecommons.org/licenses/by/ $4.0 /)$.

\begin{abstract}
It is necessary to recognize masonry domes' behavior under gravity loads in order to strengthen, restore, and conserve them. The neutral hoop plays a crucial role in identifying the masonry dome's behavior to distinguish between its tensile and compressive regions. When it comes to determining the neutral hoop position in a dome with the same brick material, in addition to determining the dome's curve and thickness, the support condition located on the boundary line is a significant parameter that has received less attention in the past. Therefore, this research aims to comprehensively define masonry dome behaviors based on the support condition's effect on the masonry dome's behavior, in addition to thickness and curve parameters, by determining neutral hoop(s). The method is a graphical and numerical analysis to define the sign-changing positioning in the first principal stress (hoop stress), based on the shell theory and extracted from a finite element method (FEM) Karamba3D analysis of a macro-model. The case studies are in four types of supports: condition fixed, free in the $\mathrm{X}$ - and Y-axes, free in all axes (domes placed on a drum), and free in all axes (domes placed on a pendentive and a drum). For each support condition, twelve curves and four varied thicknesses for each curve are considered. Results based on the dome's variables show that, in general, four types of masonry domes behavior can be identified: single-masonry dome behavior with no neutral hoop; double-masonry dome behavior where all hoops are compressive with a single neutral hoop; double-masonry dome behavior where hoops are compressive and tensile with a single neutral hoop; and treble-masonry dome behavior with double neutral hoops.
\end{abstract}

Keywords: masonry dome behavior; neutral hoops; support conditions; dome's thickness and curves

\section{Introduction}

Domes are among the most crucial building elements that have had a robust semantic and physical application for a long time. In much of the world, granaries, storage buildings in general, ovens, kilns, ice houses, and cisterns were often built using domical structures [1].

In the analysis of masonry domes, at first, the static behavior (gravity load is the most important and most effective static load) is evaluated in general. Then, the dynamic behavior is examined from different aspects, such as seismic analysis of the dome. Many researchers have evaluated the study of dome seismicity [2,3]. The most important common point is analyzing specific case studies, which are not usable in other case studies. Therefore, over the years, gravity loads have been considered by many researchers. The behavior of masonry dome structures consists of two categories, mono- and bidimensional. In monodimensional analysis, the dome is examined in two dimensions based on independent arches' behavior. The dome forces are analyzed only from the meridian path. However, in a bidimensional analysis, the dome behavior is performed in three dimensions based on 
meridian and hoop forces. In this manner, the double-masonry dome behavior is visible through a specific hoop. Hoop forces are divided by superior hoops compressed from tensile hoops downwards [4].

However, according to Heyman's three masonry dome conditions [5], masonry has no tensile strength, but masonry's tensile strength is increased by meridian compression [4]. The tensile stress is not tolerable by the dome and appears to form some capillary cracks. Thrust does generally arise when cracking begins. The cracked dome tends to open wide along a large band and break up into slices that behave as independent pairs of semi-arches leaning on each other [6]. This issue is shown in Figure 1b.

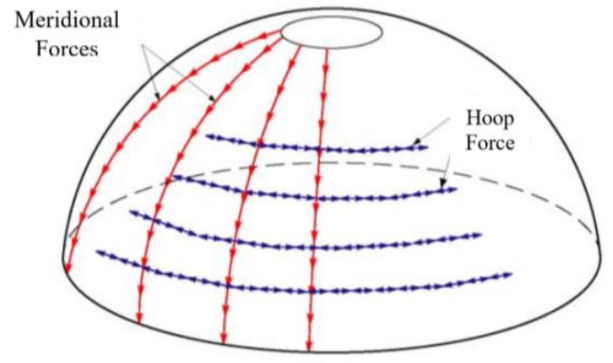

(a)

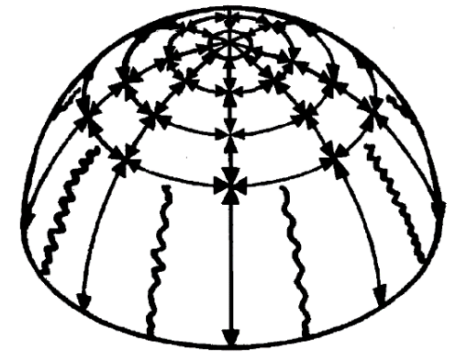

(b)

Figure 1. (a) Force type of dome structures; (b) meridional and hoop load paths for a masonry dome cracked in its lower sections only. Adapted from "Statics of Historic Masonry Constructions" written by Mario Como [6] and "The Digital Workflow of Parametric Structural Design - Developing Grid Shells in a Nordic Climate" written by Marie Eliassen and Åshild Huseby [7].

According to Figure 1a, two types of force can resist the applied loads on the dome. Today, meridian and hoop lines are the primary paths that transfer loads to the dome's supports. Meridian forces are always in compression, and their magnitude increases from the crown to the base for any dome that is loaded asymmetrically by self-weight. The main conflict is on the hoop forces in the dome. Consequently, some of the hoop forces are compressive, and others are in tension. Therefore, in almost all analyses, the changing state of hoop forces from negative (compression) to positive (tension) is called a neutral hoop.

The disadvantage of previous methods is the lack of attention to the boundary line and its support conditions. Therefore, the main issue is the influence of support conditions other than the dome's thickness and curve that sometimes cause a second neutral hoop or no neutral hoop. Notwithstanding the fact that a double-masonry dome's behavior under gravity loads with a single neutral hoop is mentioned in previous research, there is no attention to the support condition to determine the masonry dome's behavior. The novel part of this research is a comprehensive definition of masonry dome behavior consisting of single-, double-, and treble-masonry dome behavior by determining neutral hoop(s) based on support conditions in addition to various thicknesses and curves. Three types of curves are chosen: pointed (a simple and Multi-Curved), hemispherical (complete hemispherical and part of a circle), and parabolic curves. Accordingly, the historical summary of masonry dome analysis is presented. The case studies are then analyzed to find the neutral hoops and define the masonry domes' behavior. The Karamba3D toolkit (Karamba license has been purchased from www.karamba3d.com) [8,9] in the Grasshopper plug-in is the proper software for this purpose. The result of FEM Karamba3D is graphical and computational. Overall, Karamba is a self-contained Finite Element (F.E.) solver, and it exists inside Grasshopper [10]. By investigating the sign changing of the principal stress of the shell, the position of neutral hoops is determined. The final section defines the single- and treble-masonry dome behavior of the dome, in addition to the prevalent double-masonry dome behavior. 


\section{Evolution of Masonry Dome Analysis}

The evolution of masonry dome analysis started with experts considering a geometrical investigation without paying attention to the neutral hoop to formulate the neutral hoop position(s). This evolutionary process took a long time before, finally, the FEM method was used to present a wide range of attitudes in masonry dome analysis. In general, the evolutionary history of the study of masonry domes is divided into four parts, which are presented in the following:

\subsection{Primitive Analysis of Masonry Dome without Considering the Neutral Hoop}

The history of masonry dome analysis based on monodimensional arch dates back to B.C. Therefore, Table 1 is a historical summary of geometry and catenary analysis of masonry domes so that analysis is not affected by the neutral hoop(s).

Table 1. Primitive attempts of researchers on masonry domes without considering the neutral hoop.

\begin{tabular}{|c|c|}
\hline \multicolumn{2}{|r|}{ The Geometry and the Construction Techniques } \\
\hline $\begin{array}{l}\text { Vitruvius (25-32 B.C.) } \\
\text { Palladio in 1570, } \\
\text { Leon Battista Albert in } 1472 \\
\quad \text { Scamozzi in } 1615\end{array}$ & $\begin{array}{l}\text { They focused on defining the geometry and the construction techniques mentioned by } \\
\text { Palladio [11] and Scamozzi [12]. }\end{array}$ \\
\hline Huerta, 2008 & $\begin{array}{l}\text { Huerta conducted a comprehensive investigation of the historical evolution of theories } \\
\text { on vaulted structures [13]. }\end{array}$ \\
\hline \multicolumn{2}{|r|}{ Catenary Form } \\
\hline Hooke [14] & $\begin{array}{l}\text { Hooke was the first one to highlight the analogy between the thrust line of a } \\
\text { compressed arch and the shape of an inverted catenary [15-17]. The hanging chain } \\
\text { represented forces in only two dimensions [18] and obtained the thrust line of arches } \\
\text { by a funicular shape. }\end{array}$ \\
\hline $\begin{array}{l}\text { Schodek [19] } \\
\text { Xie, Felicetti, and Tang [20] }\end{array}$ & Described funicular structural systems in detail. \\
\hline Milutin Milankovitch & Milankovitch presented a remarkable formulation for the thrust line of arches [21]. \\
\hline J. Bernoulli in 1704 & $\begin{array}{c}\text { Bernoulli showed that an arch with the shape of an inverted catenary, regardless of its } \\
\text { thickness, resists its weight [22]. }\end{array}$ \\
\hline Bouguer (1734) & $\begin{array}{l}\text { Bouguer's argument lies in the fact that a dome, whose shape is obtained by rotating } \\
\text { the funicular meridian around a vertical axis, has the same property as the arch } \\
\text { analyzed by Bernoulli [23]. }\end{array}$ \\
\hline Poleni, In the mid-eighteenth century & $\begin{array}{l}\text { Poleni is one of the first recorded to formally analyze domes, and he used static } \\
\text { analysis to assess meridional cracks in the dome [18]. }\end{array}$ \\
\hline $\begin{array}{l}\text { Benvenuto [24] } \\
\text { Bossut [25] } \\
\text { Coulomb [26] } \\
\text { Mascheroni [27] } \\
\text { Salimbeni [28] }\end{array}$ & $\begin{array}{l}\text { Embraced the approach of Bouguer and developed a few new aspects. They assumed } \\
\text { masonry domes to be made of a set of independent arches, disregarding hoop forces. }\end{array}$ \\
\hline
\end{tabular}

\subsection{Single Neutral Hoop (Double-Masonry Dome Behavior) Roles in Masonry Dome Analysis}

The common frame of reference for ancient researchers is a monodimensional behavior structure for masonry domes. They considered them to be distinct segments or slices or "lunes", broad at the base and tapering to zero at the crown. It is concluded that in these pieces of research, if the stability of each element of slices is proven, the original structure must be stable. However, for this method to be accurate, masonry behavior must be treated as bidimensional. In bidimensional analysis, masonry domes' stability is considered in meridian and hoop paths. Table 2 presents a summary of researchers' attempts on this subject. 
Table 2. Research on the single neutral hoop role in masonry dome analysis.

\begin{tabular}{|c|c|}
\hline Researcher(s) & Researchers' Views and Theories \\
\hline $\begin{array}{l}\text { Poleni and Arroyo [29] and } \\
\text { some mathematicians }\end{array}$ & $\begin{array}{l}\text { Poleni and Arroyo showed a severe damage crack pattern that opened the first rigorous scientific } \\
\text { debate on the stability of masonry domes. }\end{array}$ \\
\hline Navier $[30,31]$ & Navier worked on elasticity theory. \\
\hline Heyman [32] & $\begin{array}{c}\text { Heyman noted on this issue, "The imperfections of the real world would make it unlikely that } \\
\text { linear elastic behavior will occur." }\end{array}$ \\
\hline Como Prager & $\begin{array}{l}\text { Prager suggested that elastic strains do not affect the collapse load [6]. All stresses remain } \\
\text { constant when the failure mechanism is under stress, and new elastic strains do not develop [33]. }\end{array}$ \\
\hline Geckeler [34] & $\begin{array}{l}\text { Geckeler published a simplified form of the membrane theory equations in his physic } \\
\text { handbook, Elastosiatik. }\end{array}$ \\
\hline Truesdell [35] & $\begin{array}{l}\text { Truesdell cited Geckeler in claiming that the reason for the membrane theory's success is its } \\
\text { simplicity in contrast to that of the bending theory. }\end{array}$ \\
\hline Schwedler [36] & $\begin{array}{l}\text { Schwedler explicitly introduced the concept of a bidimensional behavior of domes, providing a } \\
\text { detailed graphical solution to the problem [4]. }\end{array}$ \\
\hline Beltrami [37] & $\begin{array}{c}\text { Beltrami [37] developed membrane theory, which Tempesta mentions, as well as Paradiso, } \\
\text { Galassi, and Pieroni [22]. }\end{array}$ \\
\hline Wolfe [38] & $\begin{array}{l}\text { Wolfe published a graphical method similar to Schwedler's membrane-theory-based graphical } \\
\text { method that, similarly to membrane theory, is conservative due to its constraint of the thrust line } \\
\text { to the dome's median radius [18]. Wolfe described his method in Graphical analysis: A textbook on } \\
\text { graphic statics [39]. }\end{array}$ \\
\hline Eddy & $\begin{array}{l}\text { According to Eddy's }[40,41] \text { calculation on a hemispherical dome loaded axisymmetrically, the } \\
\text { transition between compressive hoop forces near the crown and tensile hoop forces near the base } \\
\text { occurs at } 51^{\circ} 49^{\prime} \text { from the axis of rotation [4]. Eddy considered the thrust line in the middle third } \\
\text { of a dome so that "upper part of the dome [to] be then carried by the [lower part] as a series of } \\
\text { masonry arches standing side by side" [40]. }\end{array}$ \\
\hline
\end{tabular}

\subsection{An Important Step for Masonry Dome Analysis}

A comprehensive modern research study on membrane theory was presented by Cavalagli and Gusella [42]. They studied a masonry pointed dome with a lantern using a membrane method, proving this method's applicability in various domes.

Billington [39], based on Schwedler's method, defined four primary assumptions for membrane theory:

1. Applied loads are resisted by internal forces within the surface, which have no stiffness against bending; therefore, internal forces are either pure tension or pure compression;

2. On asymmetrically and uniformly loaded domes, internal forces act perpendicularly to each other in the meridional and latitudinal, or hoop, directions;

3. Internal forces are coplanar; that is, the membrane has zero thickness;

4. The membrane plane is located along the centerline of the dome's adequate thickness; thus, the thrust lines must also lie on this median surface.

The latter two assumptions, which constrain the location of the thrust line to the median radius and reduce the dome's thickness to zero, limit hoop force values to those needed to equilibrate meridional forces; as a result, the membrane solutions tend to underestimate the dome's ability to attain stability [18].

Other applicable studies in this issue were presented by Heyman [43], who first considered an entire hemisphere, i.e., the value of the first principal stress change sign to be at $\varnothing=51.8^{\circ}$. For $\varnothing>51.8^{\circ}$, tensile stresses are developed in the hoop direction. The angle between the neutral hoop and the boundary line is equal to $38.2^{\circ}$.

Generally, membrane elements are used to represent only the in-plane stiffness of members, acting like bedsheet. The bedsheet does not have any bending stiffness, and so, it bends without any resistance. However, on the other hand, shell elements are more realistic for any structural wall or a slab or basement wall. They have in-plane and out-of-plane stiffness. Como's equations are comprehensive, taking into consideration the thickness of the shell in membrane theory. 
Membrane theory can also be used to examine the thickness shell in masonry domes via the finite element method, considering all aspects of masonry dome properties.

The critical theory used in this paper is shell theory. Shell theory is similar to membrane theory. Membrane theory is permissible only for shells that cannot be bent extensionally or shells that experience only tiny bending moments. However, in shell theory, membrane forces, moments, and shear forces are also essential to consider. Figure 2a,b explains all the forces calculated in the shell [44].

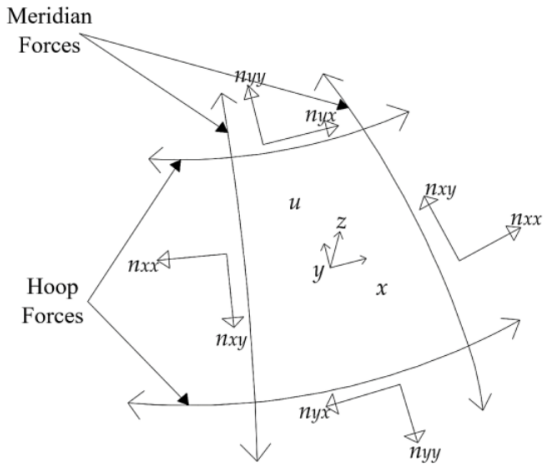

(a)

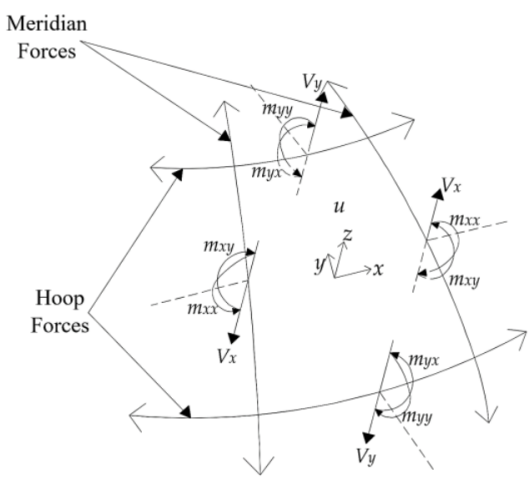

(b)

Figure 2. (a) Local membrane forces; (b) local moments and shear forces. Adapted from "Structural Shell Analysis, Understanding and Application", written by Johan Blaauwendraad and Jeeroen H. Hoefakker [45].

\subsection{Numerical Analysis of Masonry Domes without Considering the Neutral Hoop}

Farshad [46] defined a nonstretched dome behavior employing membrane theory. Farshad [47] also published a book on the issue of shell structures. Robison [48] believed that the current prevalent method to design and analyze thin-shell and dome structures is numerical (FEM) computer software. The FEM method can reveal more than the primary membrane and bending theories. For example, Robison [48] implemented the FEM method on St. Peter's Dome, and his findings were consistent with Poleni's research.

Recent research pieces have been dedicated to numerical methods that analyze masonry domes as rigid bodies in continuous and discrete forms. Some of these numerical methods are the Arc Length and Newton-Raphson method. The arc-length method or Modified Riks method is an alternative method that can be used to solve static nonlinear problems [49]. The arc-length method is a powerful solution technique becoming increasingly popular among more general formulation researchers and engineers. The arc-length method is derived in its continuous and discrete formulations [50], and it is a solution strategy in which the path, through a converged solution, at any step, follows a direction orthogonal to the tangent of the solution curve. In this procedure, both the load vector and the displacement field vary [50].

The other method is the Newton-Raphson method. This method has been implemented on masonry buildings such as Mosca's bridge in Turin, and the outcomes of this effort are very significant. Generally, Newton-Raphson as a numerical method has been suggested to solve masonry-like solids' equilibrium problem with bounded compressive strength. In particular, the derivative of the stress concerning the total strain is calculated; this derivative can be used to calculate the tangent stiffness matrix and then solve the nonlinear system, obtained through discretization into finite elements via the NewtonRaphson method [51]. The Newton-Raphson approach can be used in a single degree of freedom nonlinear analysis. The ANSYS program uses Newton-Raphson equilibrium iterations to update the model stiffness [52].

The Newton-Raphson method is comprehensively described by Yang [53] in Chapter 20- "Numerical Methods of Engineering Mathematics with Examples and Applications". 
Since masonry dome calculation is an interdisciplinary concept of architects and structural engineers, in recent years, attempts have been made to create computational software with graphical properties that consider the geometry of domes and materials' mechanics.

Many pieces of software have been developed based on the needs of structural and architectural design. In most cases, architects and structural engineers use separate software. However, today, building information modeling (BIM) knowledge has helped $\mathrm{t}$ develop coherence between the different approaches that engineers use in building design. Rhinoceros software, for example, has the ability to link between engineers through its plug-ins and toolkit. Therefore, the Rhinoceros software and Grasshopper plug-in were used here. Generally, this program is a bridge between architectural and structural design, facilitating collaboration between architects and engineers at the early stages of building design. Grasshopper is based on parametric and algorithmic design, which assists programmers in helping engineers in various aspects. Overall, parametric design programs such as Grasshopper (G.H.) for Rhino or Generative Components popularized this approach by providing easy-to-use visual programming environments that integrate with computer-aided design (CAD) packages [10]. Many toolkits are developed in Grasshopper. However, in terms of structural analysis, Karamba3D is a finite element (F.E.) program for predicting the behavior of structures under external loads. Though developed by a structural engineering firm, its primary focus does not lie in this field. It is geared toward use within an interactive, parametric architectural design environment [54].

\section{Method}

The method used in this study is a graphical and numerical analysis based on the algorithm in parametric engineer software. The sign-changing position of first principal stress (p.s o1) shows the accurate position of neutral hoops on domes. To obtain it, the FEM Karamba3D 1.3.3 build 201012 developed by Clemens Preisinger in collaboration with Bollinger + Grohmann Engineers, Frankfurt, Germany in Grasshopper 1.0.0007 plug-in for Rhino 7 software is used. In this research, the Newton-Raphson method [51] has been chosen because it is used to solve finite element equations in some software such as ANSYS, which is prevalent and reliable in engineering analysis.

According to the FEM output, it is possible to draw the first principal stress diagram for domes with a specific thickness with two axes; the horizontal axis is the dome's radius, and the vertical axis is the first principal stress value. The neutral point projection on the dome is the intersection point(s) of the first principal stress and the X-axis. Then, by drawing vertical lines from the neutral point projection, the dome's intersection with the vertical line(s) is marked. These points are the neutral points on the dome. After finding the point(s) on the dome, the dome's neutral point angle and boundary line are available. The parallel plane(s) with the dome's base, through the neutral point(s), is the location of the neutral hoop(s) on the dome. This process is described below.

Karamba3D is fully embedded in the parametric design environment of Grasshopper, a plug-in for the 3D modeling tool Rhinoceros. This plug-in makes it easy to combine parameterized geometric models and finite element calculations [8].

This software analyzes the model through the following steps. The first step defines the dome model's physical properties. After that, the dome material's mechanical properties are determined. There are various parameters in Karamba3D that must be considered before analysis can be conducted. These include determining the structural elements, support, loads, materials, and cross-section.

Assembling all the information is the final part of the first step. The first part of the pre-analysis is the determination of the type of analysis. Finally, the relevant components extract the results.

Figure 3 specifies the determination of neutral hoops' location in five steps. Step 1 presents a diagram of the first principal stress (p.s $\sigma 1$ ). Step 2 presents an intersection of the p.s $\sigma 1$ diagram and the $\mathrm{X}$-axis. The $\mathrm{X}$-axis is the dome's radius, and the " $\mathrm{O}$ " at the center of the dome's base circle is zero. Step 3 shows the vertical lines passing through the point(s) 
of the previous step. Step 4 is the point(s) of the neutral hoop(s) on the dome. Box 5 shows how to measure the angles of neutral lines.

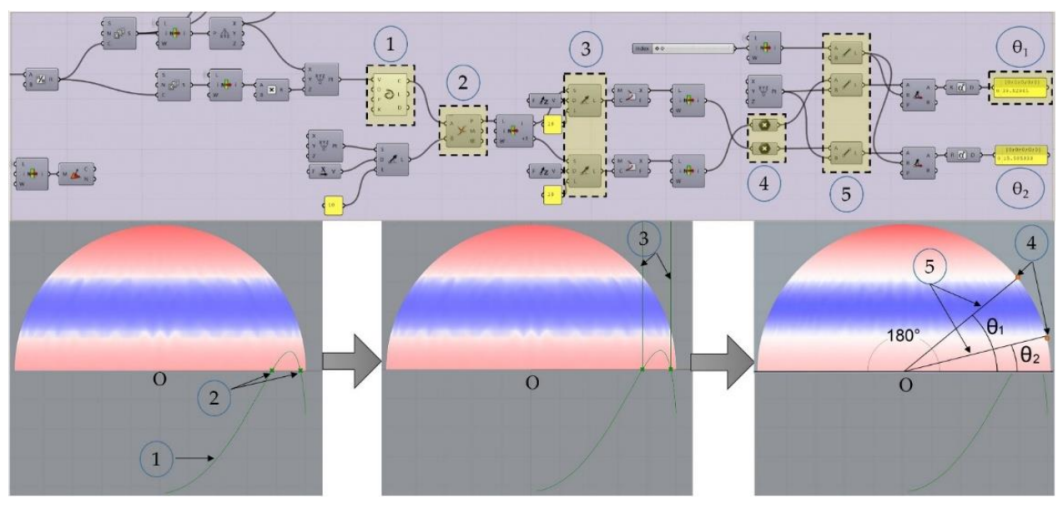

Figure 3. Position of neutral hoops on domes (sample: hemispherical dome with fixed supports).

After a graphical and numerical analysis of the case studies, in the end, using the Eddy and Lévy method, it is possible to define masonry dome behavior.

\section{New Perspective of Masonry Dome Behavior}

The primary debate on the analysis of masonry domes is the definition of the force path. Most former research, especially that conducted by the Massachusetts Institute of Technology (MIT) group [55], and including mono- and bidimensional methods, considered a neutral hoop that divides the dome's hoop stress into two parts: compression and tension.

The main conflict here is the definition of masonry dome behavior based on the support condition on the boundary line and the number of neutral hoops in masonry domes. Masonry domes are always constructed on earth, drums, and pendentives. Nevertheless, how the dome is placed on the underlying structure is very important. The main applied force by the dome to the underlying structure is the thrust line. The thrust line comprises two components, the horizontal and the vertical. In addition to the dome's thickness and curve, when the support resists against the horizontal component of the thrust line, the number and the position of the neutral hoop(s) are affected. Section 4.3 presents the influence of these parameters on the masonry dome.

As the analysis method is FEM, the mechanical properties of the material are needed. Accordingly, before analyzing the case studies, the material properties are presented.

\subsection{Initial Information of Masonry Dome Analysis}

To analyze masonry domes, material properties and analysis information are essential, along with physical parameters. The first step is to determine the mechanical properties of the material. Since material properties vary and depend on geography and climate, Iranian brick material has been chosen because it includes many ancient and historical buildings, especially in the Middle East and in Middle and South Asia, in ancient Iranian regions. Therefore, the employed information is based on investigations and experiments performed on Iranian building materials. There are two main finite element modeling approaches to analyze masonry structure: macro-models and micro-models [56]. The approach used here is macro-models [57,58]. In this article, masonry material is considered to be isotropic material with equivalent mechanical properties [56]. As per Table 3, the mechanical properties of brick-and-mortar combinations are the focus of this research. 
Table 3. Mechanical properties of Iranian masonry dome material. Data from Mehrdad Hejazi and his research group at the University of Isfahan $[59,60]$.

\begin{tabular}{ccccccc}
\hline $\begin{array}{c}\text { Mechanical } \\
\text { Properties }\end{array}$ & $\begin{array}{c}\text { Specific } \\
\text { Weight }\end{array}$ & $\begin{array}{c}\text { Young's } \\
\text { Modulus }\end{array}$ & Poisson's Ratio & $\begin{array}{c}\text { Tensile } \\
\text { Strength }\end{array}$ & $\begin{array}{c}\text { Compressive } \\
\text { Strength }\end{array}$ & $\begin{array}{c}\text { Coefficient of } \\
\text { Thermal Expansion }\end{array}$ \\
\hline masonry & $\begin{array}{c}15.004 \\
\left(\mathrm{KN} / \mathrm{m}^{3}\right)\end{array}$ & $\begin{array}{c}273 \\
\left(\mathrm{KN} / \mathrm{cm}^{2}\right)\end{array}$ & 0.17 & $\begin{array}{c}0.027 \\
\left(\mathrm{KN} / \mathrm{cm}^{2}\right)\end{array}$ & $\begin{array}{c}0.273 \\
\left(\mathrm{KN} / \mathrm{cm}^{2}\right)\end{array}$ & $0.6 \times 10^{-5}$ \\
\hline
\end{tabular}

The shear modulus is calculated via Equation (1):

$$
S=E /(2 \times(1+V))
$$

where $E$ is Young's Modulus and $V$ is Poisson's ratio. According to Table 3, $S$ equals to $116.67\left(\mathrm{KN} / \mathrm{cm}^{2}\right)$.

The yield strength is the stress level, where the material starts to strain plastically. The comparison between analytical and experimental results shows the relationship's reliability for calculating the elastic modulus $\varepsilon$ of masonries relative to the first branch of the bilinear $\sigma-\varepsilon$. This possibility concerns only masonries for which $\sigma-\varepsilon$ behavior can be considered to be linearly elastic for at least up to $75 \%$ of failure stress [61,62].

According to previous research and the masonry structures' analysis, the only applied load is dead load because the critical issue is the dome's weight. The safety factor for dead load analysis is considered at 1.2.

\subsection{Case Studies}

As the chosen material is in the Middle East and Middle and South Asia, the curves are based on this region and consist of some pointed, parabolic, and hemispherical forms. In this research analysis, twelve curves of known masonry domes have been analyzed in four varied support conditions: fixed, free in $X$ and $Y$, free in all axes (domes placed on a drum), and free in all axes (domes placed on a drum with a pendentive). Figure 4 illustrates all the different kinds of support condition considered in this study:

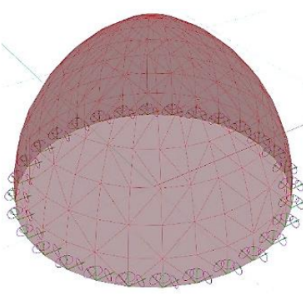

(a)

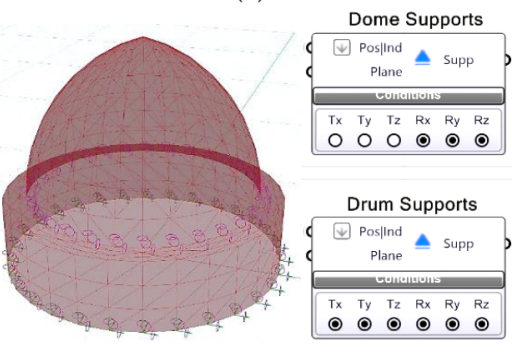

(c)
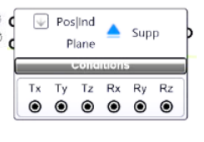

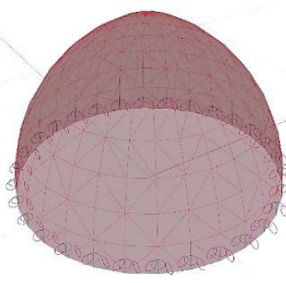

(b)
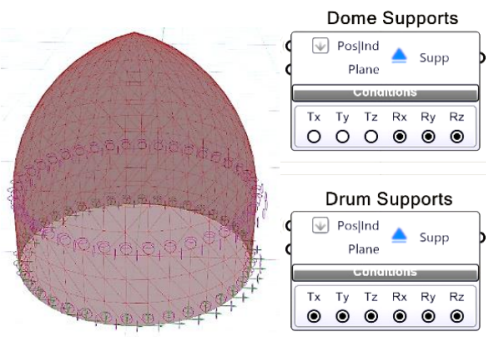

(d)

Figure 4. (a) Fixed, and (b) free in $X$ and $Y$; (c) free in all axes (domes placed on a drum with a pendentive); (d) free in all axes (domes placed on a drum).

In all the case studies, various constant thicknesses are considered to comprehensively determine all the different masonry dome behavior states.

The masonry dome curves considered are hemispherical and pointed in various curves with constant thickness in the first part. The physical properties are $t_{\text {dome }}=90 \mathrm{~cm}$, 
$R_{m}=5 \mathrm{~m}$, and $t_{\text {dome }} / R_{m}=0.18$. $t_{\text {dome }}$ is the thickness of domes; $R_{m}$ is the medium radius, which is the thrust line's location. $H_{\text {drum }}$ is the drum's height, $t_{\text {drum }}$ is the drum's thickness, $R_{\text {drum }}$ is the drum's radius, and $R_{\text {Drum with pendentive is the drum's radius with }}$ the pendentive.

In Tables 4-11, the case studies have been divided into fixed support, free support in the $\mathrm{X}$ - and $\mathrm{Y}$-axes, free support in all axes (domes placed on a drum), and free in all axes (domes placed on pendentive and drum).

The first principal stress (p.s $\sigma 1$ ) is related to the hoop stress, whose sign changing divides the dome hoop stress into two kinds of compression and tension. The p.s $\sigma 2$ is related to meridian stress, which is always in compression and is not useful for the research goal.

\subsubsection{Fixed Support}

In fixed support placed on the dome's boundary line, there is movement restriction in all directions. Tables 4 and 5 present fixed support with various curves and thicknesses. Table 4 presents the maximum compression and tension of hoop stress (p.s $\sigma 1$ ) and the angle between the neutral hoop(s) and the dome's boundary line, with domes with $90 \mathrm{~cm}$ constant thickness.

According to Table 4, the results are as follows:

1. In the dome, its curve is part of the circle $-133^{\circ}$ out of $360^{\circ}$-all hoops are in compression, and there is no neutral hoop;

2. In the dome, its curve is part of the circle $-167^{\circ}$ out of $360^{\circ}$-all hoops are in compression, and there is a single neutral hoop;

3. Except for the previous case studies, in other domes, there are double neutral hoops. Hoops are in tension in the blue color zone, and hoops are compressed in the red color zone;

4. As the height-to-span ratio decreases (the horizontal vector of the thrust line increases), the tension zone decreases, finally reaching zero.

According to Table 5, the results are as follows:

1. In the dome, its curve is part of the circle- $133^{\circ}$ out of $360^{\circ}$-and increasing the thickness does not affect the number of neutral hoops. All hoops are in compression, and there is no neutral hoop;

2. In the dome, its curve is part of the circle $-167^{\circ}$ out of $360^{\circ}$; there are double neutral hoops (hoops are in compression and tension) by decreasing the dome's thickness from a thickness of $90 \mathrm{~cm}$. There is a single neutral hoop in thickness of $90 \mathrm{~cm}$, and hoops are in compression. There is no neutral hoop in the thickness of more than $90 \mathrm{~cm}$, and all hoops are in compression;

3. In the dome, its curve is part of the circle $-227^{\circ}$ out of $360^{\circ}$; there are always double neutral hoops. Changing the dome's thickness does not affect the number of neutral hoops;

4. In domes other than those mentioned above, there is a single neutral hoop in a specific thickness; for less than this thickness, there are double neutral hoops, and for more than this thickness, there is no neutral hoop. 
Table 4. Analysis of domes with fixed support $-R_{m}=5 \mathrm{~m}, \mathrm{t}_{\mathrm{dome}}=90 \mathrm{~cm}, \mathrm{t}_{\mathrm{dome}} / \mathrm{d}_{\mathrm{m}}=0.09$.

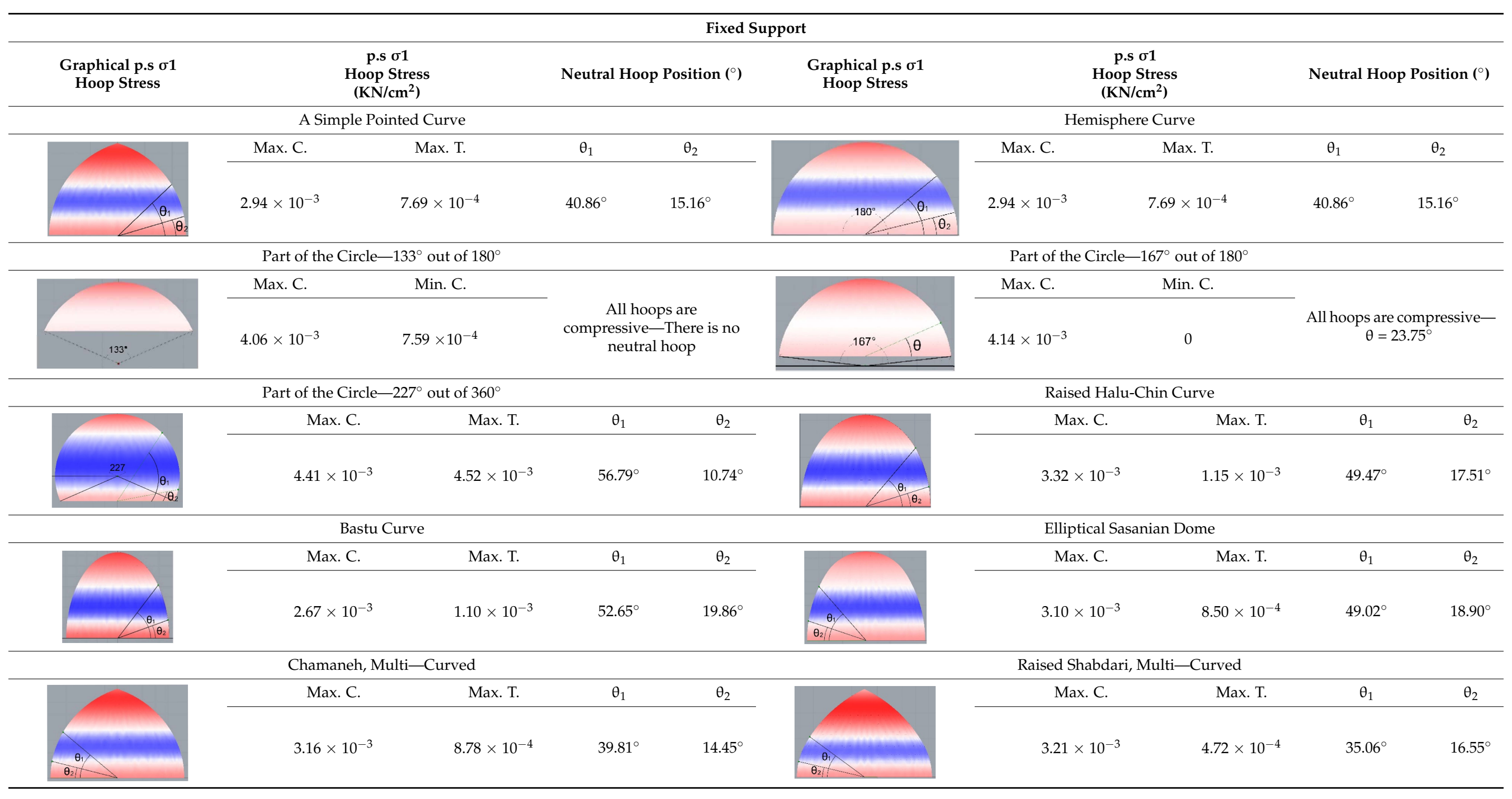


Table 4. Cont.

\begin{tabular}{|c|c|c|c|c|c|c|c|c|}
\hline \multicolumn{9}{|c|}{ Fixed Support } \\
\hline $\begin{array}{l}\text { Graphical p.s } \sigma 1 \\
\text { Hoop Stress }\end{array}$ & \multicolumn{2}{|l|}{$\begin{array}{c}\text { p.s } \sigma 1 \\
\text { Hoop Stress } \\
\left(\mathrm{KN} / \mathrm{cm}^{2}\right)\end{array}$} & Neutral Hoop Position $\left({ }^{\circ}\right)$ & $\begin{array}{l}\text { Graphical p.s } \sigma 1 \\
\text { Hoop Stress }\end{array}$ & \multicolumn{2}{|l|}{$\begin{array}{c}\text { p.s } \sigma 1 \\
\text { Hoop Stress } \\
\left(\mathrm{KN} / \mathrm{cm}^{2}\right)\end{array}$} & \multicolumn{2}{|c|}{ Neutral Hoop Position $\left(^{\circ}\right)$} \\
\hline & Max. C. & Max. T. & $\theta_{2}$ & & Max. C. & Max. T. & $\theta_{1}$ & $\theta_{2}$ \\
\hline$\theta_{1}$ & $4.31 \times 10^{-3}$ & $4.18 \times 10^{-4}$ & $12.5^{\circ}$ & $\frac{\theta_{1}}{\theta_{2}}$ & $4.67 \times 10^{-3}$ & $5.1 \times 10^{-4}$ & $31.08^{\circ}$ & $13.95^{\circ}$ \\
\hline
\end{tabular}

Table 5. Analysis of domes with fixed support and various thicknesses- $R_{m}=5 \mathrm{~m}$.

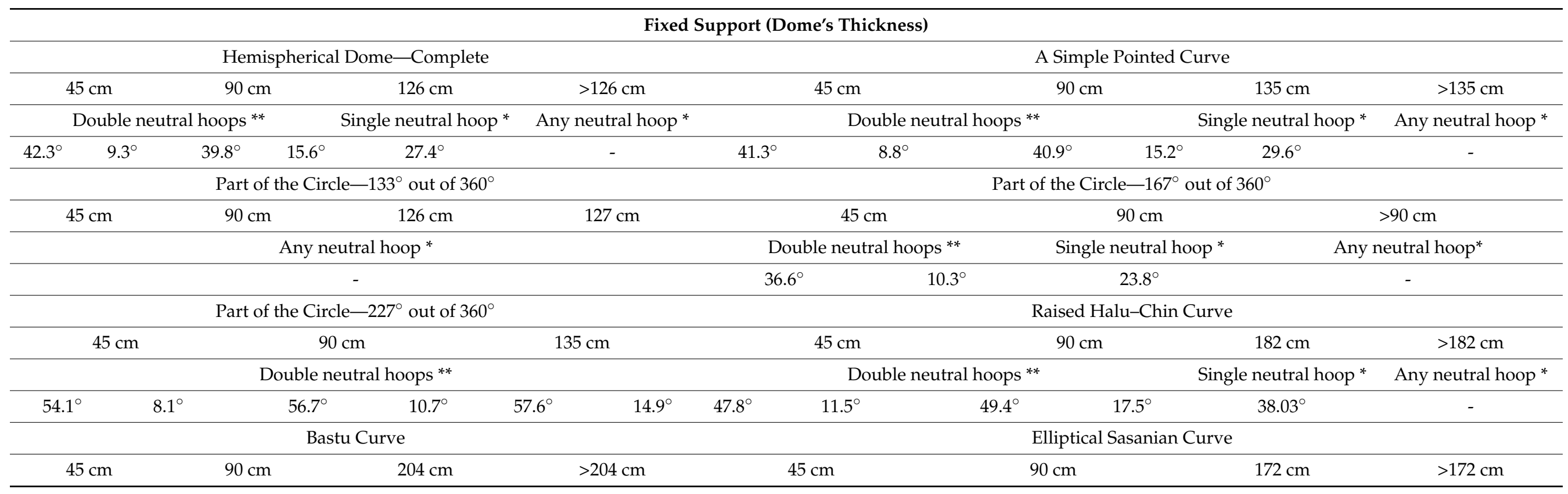


Table 5. Cont.

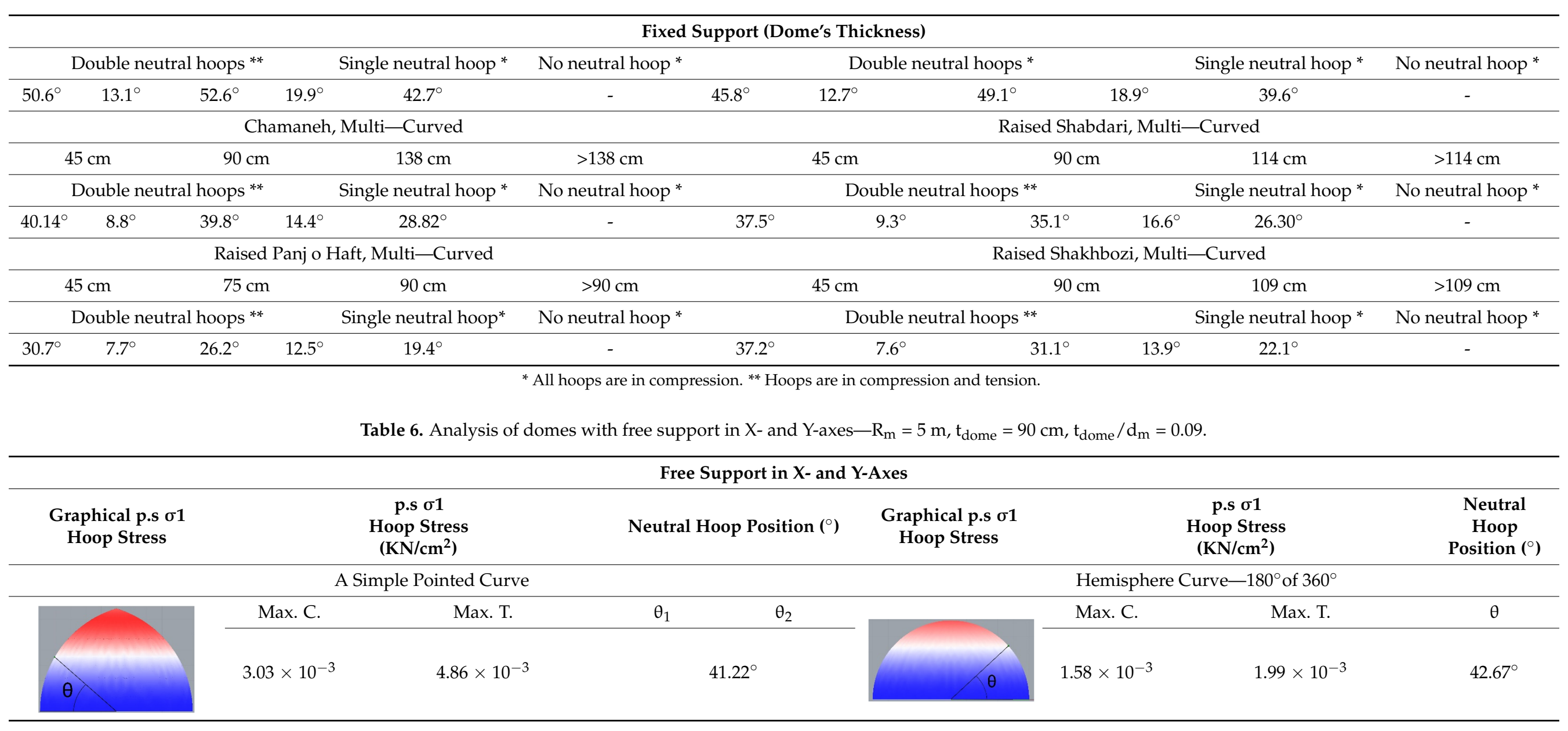


Table 6. Cont

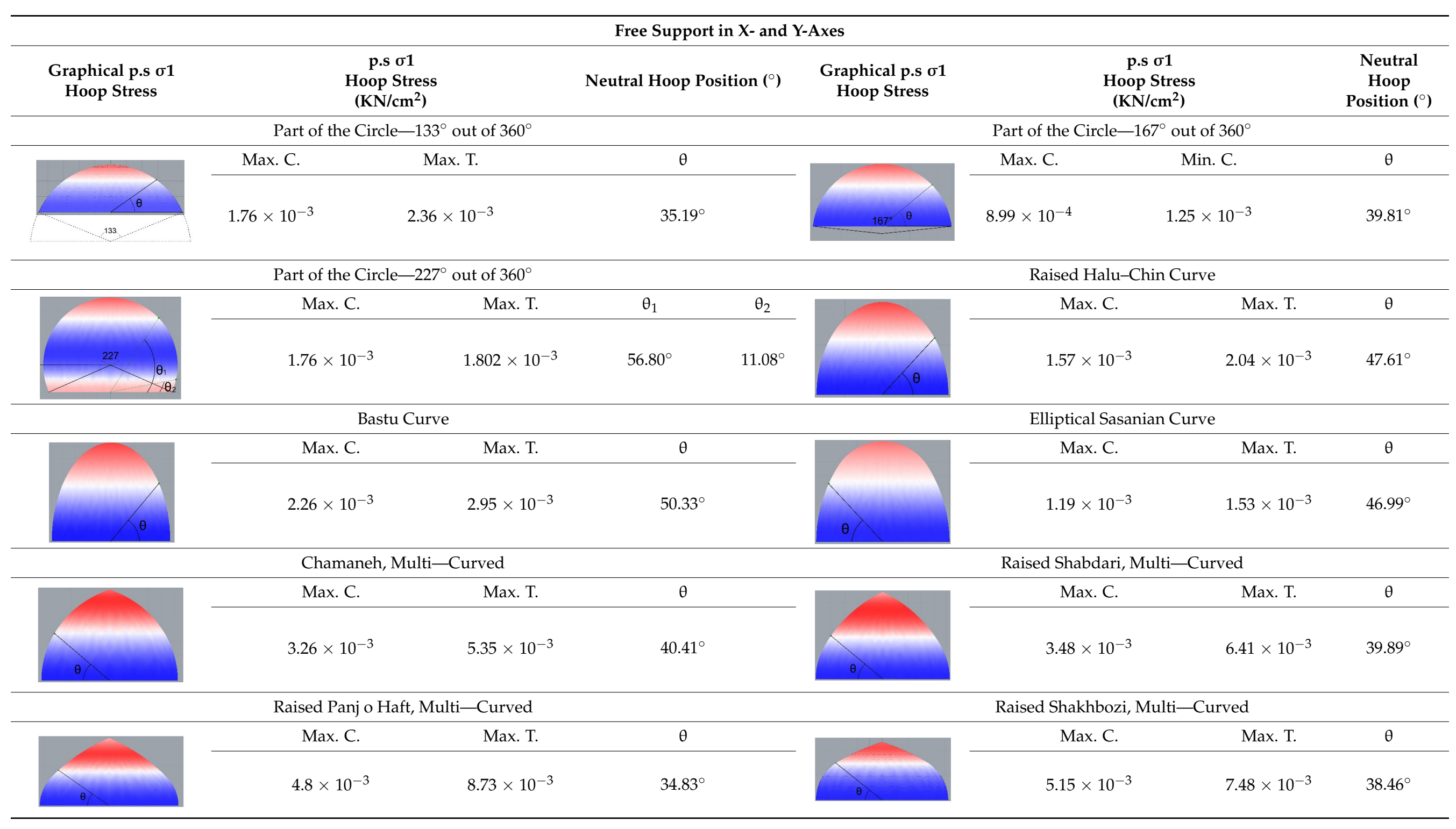


Table 7. Analysis of domes with free support in X- and Y-axes and various thicknesses- $R_{m}=5 \mathrm{~m}$.

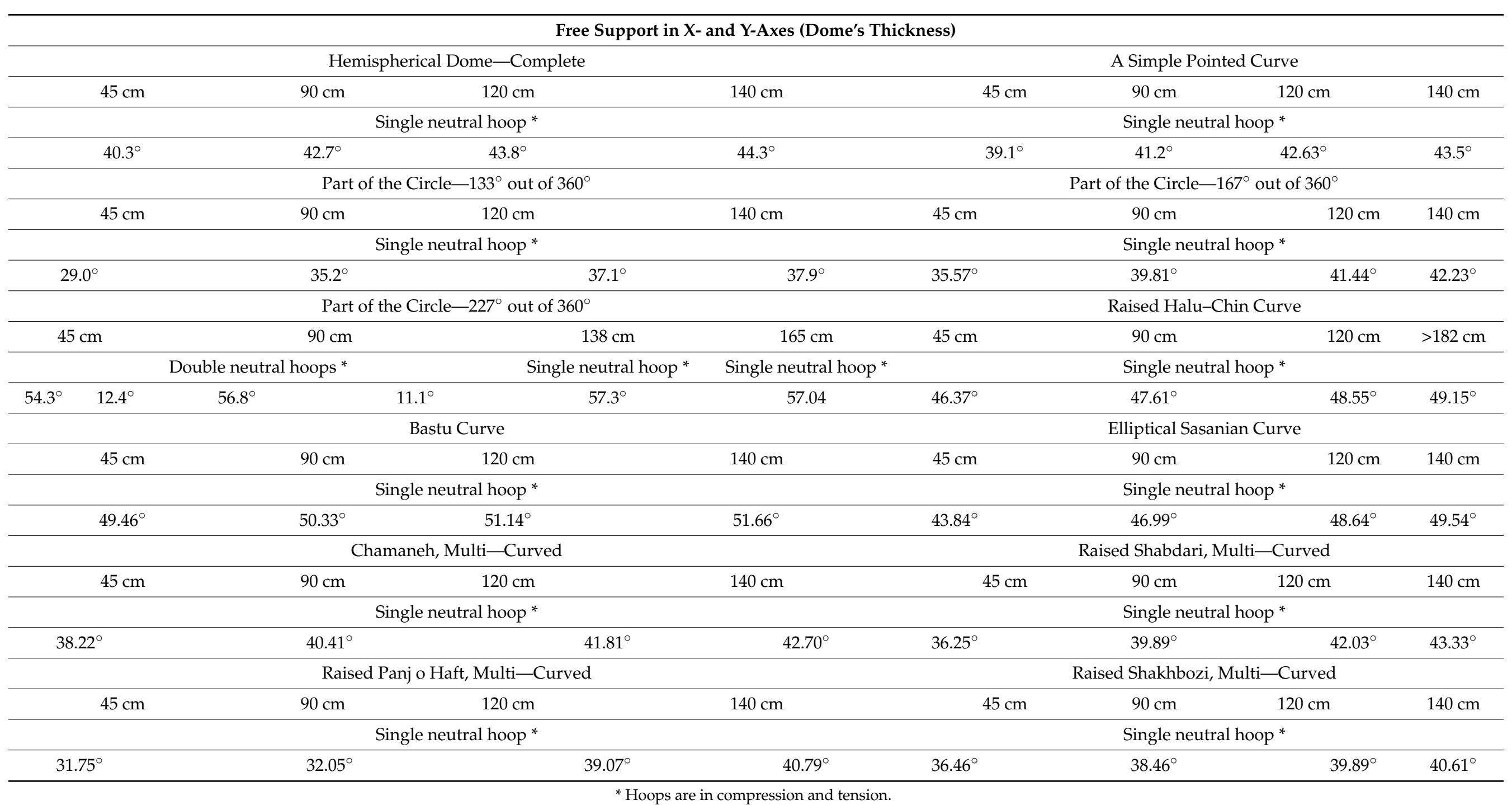


Table 8. Analysis of domes- $R_{m}=5 \mathrm{~m}, \mathrm{t}_{\text {dome }}=90 \mathrm{~cm}, \mathrm{t}_{\text {dome }} / \mathrm{d}_{\mathrm{m}}=0.09, \mathrm{H}_{\text {drum }}=3 \mathrm{~m}, \mathrm{t}_{\text {drum }}=90 \mathrm{~cm}, \mathrm{R}_{\mathrm{drum}}=5 \mathrm{~m}$.

\begin{tabular}{|c|c|c|c|c|c|c|c|}
\hline \multicolumn{8}{|c|}{ Free Support in All Axes (Domes Placed on a Drum) } \\
\hline $\begin{array}{l}\text { Graphical p.s } \sigma 1 \\
\text { Hoop Stress }\end{array}$ & \multicolumn{2}{|c|}{$\begin{array}{c}\text { p.s } \sigma 1 \\
\text { Hoop Stress } \\
\left(\mathrm{KN} / \mathrm{cm}^{2}\right)\end{array}$} & Neutral Hoop Position $\left({ }^{\circ}\right)$ & $\begin{array}{c}\text { Graphical p.s } \sigma 1 \\
\text { Hoop Stress }\end{array}$ & \multicolumn{2}{|c|}{$\begin{array}{c}\text { p.s } \sigma 1 \\
\text { Hoop Stress } \\
\left(\mathrm{KN} / \mathrm{cm}^{2}\right)\end{array}$} & $\begin{array}{l}\text { Neutral Hoop } \\
\text { Position }\left(^{\circ}\right)\end{array}$ \\
\hline \multicolumn{4}{|c|}{ A Simple Pointed Curve } & \multicolumn{4}{|c|}{ Hemisphere Dome $-180^{\circ}$ of $360^{\circ}$} \\
\hline & Max. C. & Max. T. & $\theta$ & & Max. C. & Max. T. & $\theta$ \\
\hline & $2.99 \times 10^{-3}$ & $2.22 \times 10^{-3}$ & $41.03^{\circ}$ & & $4.30 \times 10^{-3}$ & $2.48 \times 10^{-4}$ & $41.97^{\circ}$ \\
\hline \multicolumn{4}{|c|}{ Part of the Circle $-133^{\circ}$ out of $360^{\circ}$} & \multicolumn{4}{|c|}{ Part of the Circle $-167^{\circ}$ out of $360^{\circ}$} \\
\hline & Max. C. & Min. T. & $\theta$ & & Max. C. & Min. T. & $\theta$ \\
\hline & $4.41 \times 10^{-3}$ & $2.96 \times 10^{-3}$ & $29.59^{\circ}$ & & $4.31 \times 10^{-4}$ & $2.68 \times 10^{-3}$ & $37.42^{\circ}$ \\
\hline \multicolumn{4}{|c|}{ Part of the Circle $-227^{\circ}$ out of $360^{\circ}$} & \multicolumn{4}{|c|}{ Raised Halu-Chin Curve } \\
\hline & Max. C. & Max. T. & $\theta_{2}$ & & Max. C. & Max. T. & $\theta$ \\
\hline$\theta_{\theta_{2}}$ & $4.4 \times 10^{-3}$ & $4.65 \times 10^{-3}$ & $56.79^{\circ}$ & & $3.30 \times 10^{-3}$ & $2.10 \times 10^{-3}$ & $48.70^{\circ}$ \\
\hline \multicolumn{3}{|c|}{ Bastu Curve } & & \multicolumn{4}{|c|}{ Elliptical Sasanian Curve } \\
\hline & Max. C. & Max. T. & $\theta$ & & Max. C. & Max. T. & $\theta$ \\
\hline$\theta$ & $2.66 \times 10^{-3}$ & $1.81 \times 10^{-3}$ & $51.68^{\circ}$ & & $3.08 \times 10^{-3}$ & $1.88 \times 10^{-4}$ & $47.73^{\circ}$ \\
\hline
\end{tabular}


Table 8. Cont.

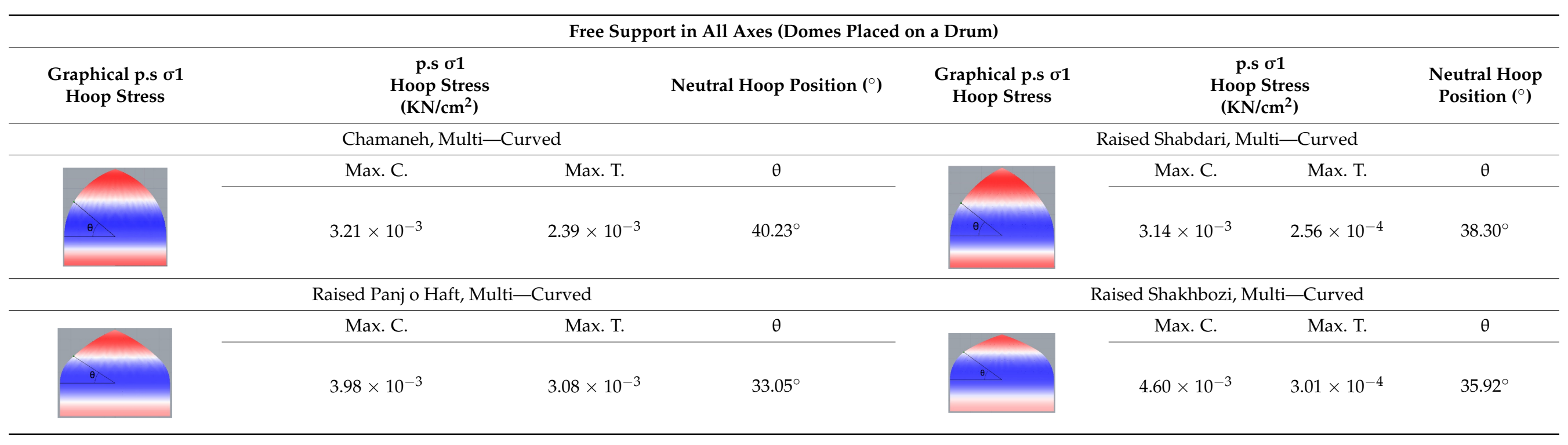

Table 9. Analysis of domes with various thicknesses $-R_{m}=5 \mathrm{~m}, \mathrm{H}_{\text {drum }}=3 \mathrm{~m}, \mathrm{t}_{\mathrm{drum}}=1.1 \times \mathrm{t}_{\text {dome }}, \mathrm{R}_{\text {drum }}=5 \mathrm{~m}$.

\begin{tabular}{|c|c|c|c|c|c|c|c|}
\hline \multicolumn{8}{|c|}{ Free Support in All Axes (Domes Placed on a Drum) (Dome's Thickness) } \\
\hline \multicolumn{4}{|c|}{ Dome-Complete } & \multicolumn{4}{|c|}{ A Simple Pointed Curve } \\
\hline $45 \mathrm{~cm}$ & $90 \mathrm{~cm}$ & $120 \mathrm{~cm}$ & $140 \mathrm{~cm}$ & $45 \mathrm{~cm}$ & $90 \mathrm{~cm}$ & $120 \mathrm{~cm}$ & $140 \mathrm{~cm}$ \\
\hline $41.34^{\circ}$ & $41.97^{\circ}$ & $41.09^{\circ}$ & $40.01^{\circ}$ & $39.84^{\circ}$ & $41.03^{\circ}$ & $41.00^{\circ}$ & $40.52^{\circ}$ \\
\hline \multicolumn{4}{|c|}{ Part of the Circle $-133^{\circ}$ out of $360^{\circ}$} & \multicolumn{4}{|c|}{ Part of the Circle $-167^{\circ}$ out of $360^{\circ}$} \\
\hline $45 \mathrm{~cm}$ & $90 \mathrm{~cm}$ & $120 \mathrm{~cm}$ & $140 \mathrm{~cm}$ & $45 \mathrm{~cm}$ & $90 \mathrm{~cm}$ & $120 \mathrm{~cm}$ & $140 \mathrm{~cm}$ \\
\hline \multicolumn{4}{|c|}{ Single neutral hoop * } & \multicolumn{4}{|c|}{ Single neutral hoop * } \\
\hline $26.31^{\circ}$ & $29.59^{\circ}$ & $29.53^{\circ}$ & $29.00^{\circ}$ & $36.19^{\circ}$ & $37.42^{\circ}$ & $36.75^{\circ}$ & $35.77^{\circ}$ \\
\hline
\end{tabular}


Table 9. Cont.

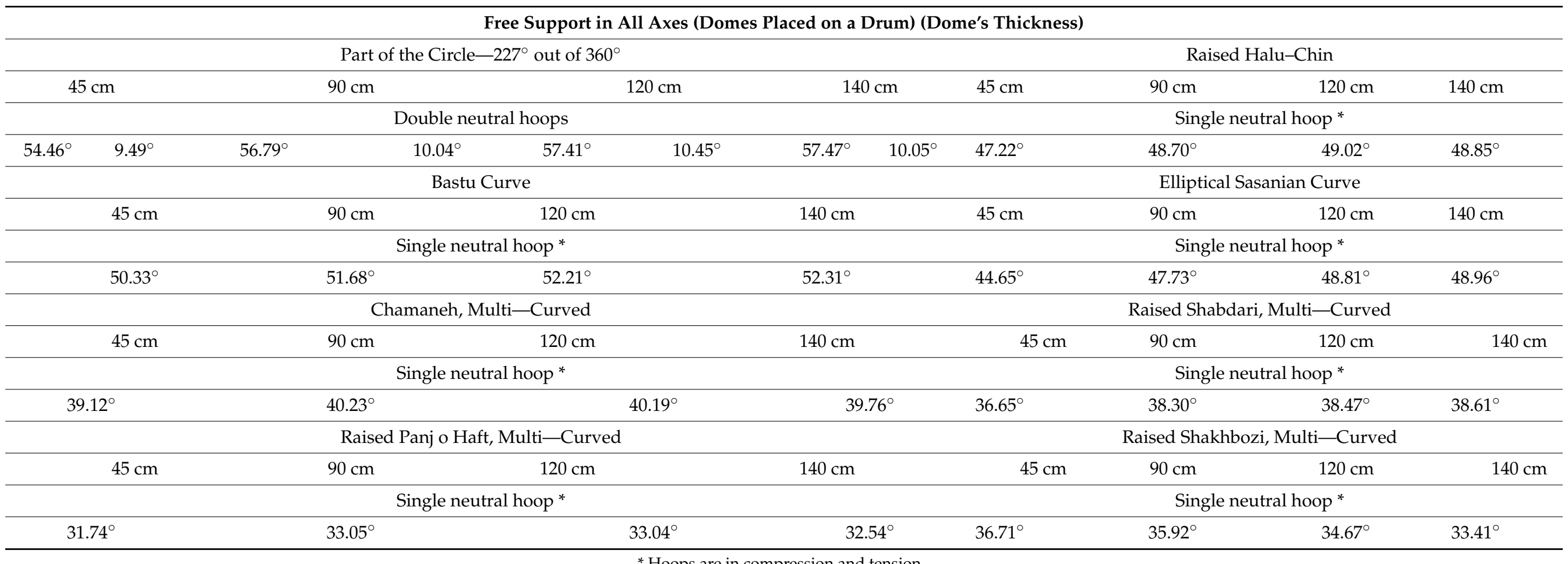

${ }^{*}$ Hoops are in compression and tension. 
Table 10. Analysis of domes $-R_{m}=5 \mathrm{~m}, \mathrm{t}_{\text {dome }}=90 \mathrm{~cm}, \mathrm{t}_{\text {dome }} / \mathrm{d}_{\mathrm{m}}=0.09, \mathrm{H}_{\text {drum }}=3 \mathrm{~m}, \mathrm{t}_{\text {drum }}=1.1 \times \mathrm{t}_{\text {dome }}, \mathrm{R}_{\text {drum }}=5 \mathrm{~m}, \mathrm{R}_{\text {drum with pendentive }}=6 \mathrm{~m}$.

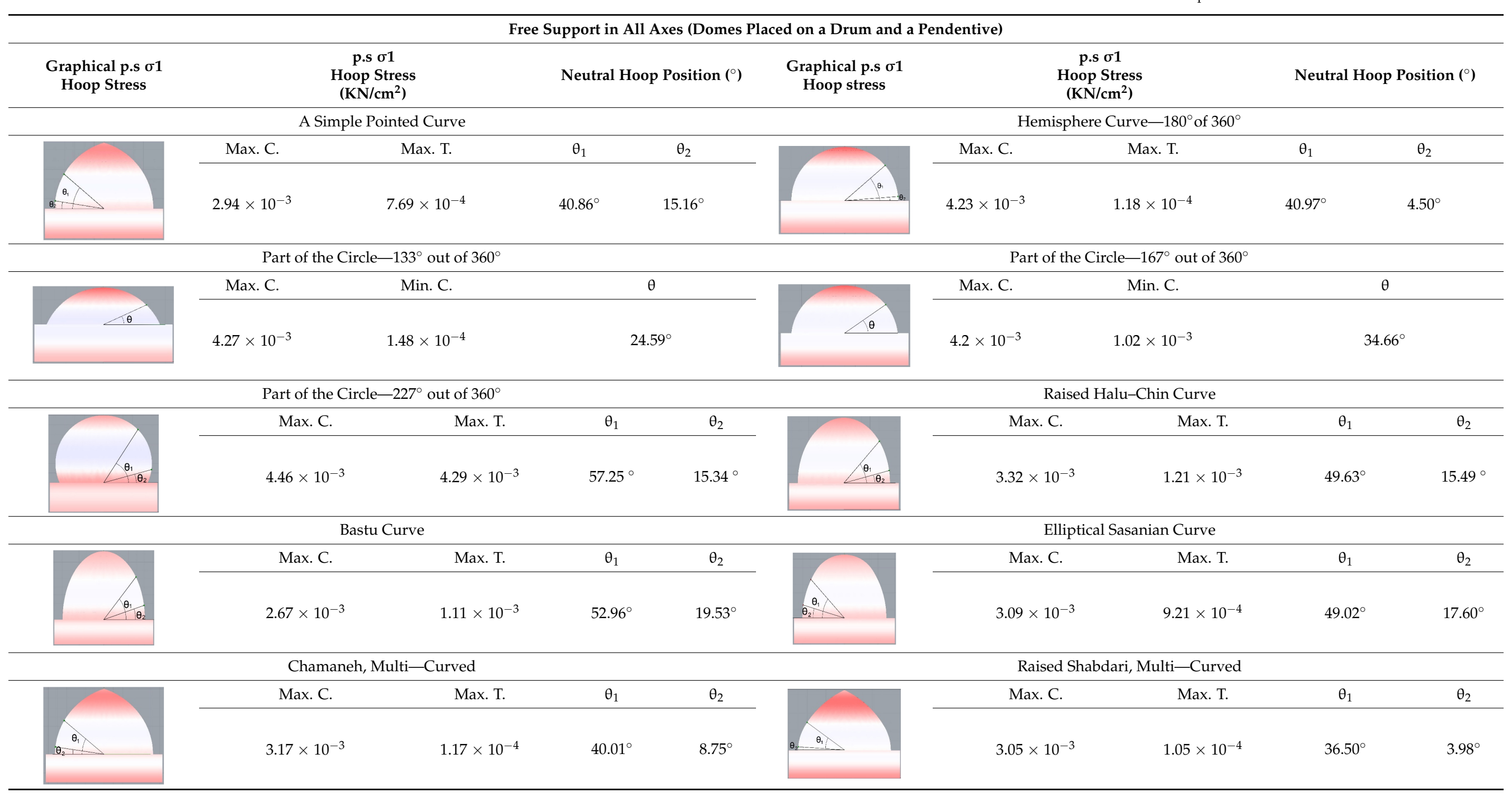


Table 10. Cont.

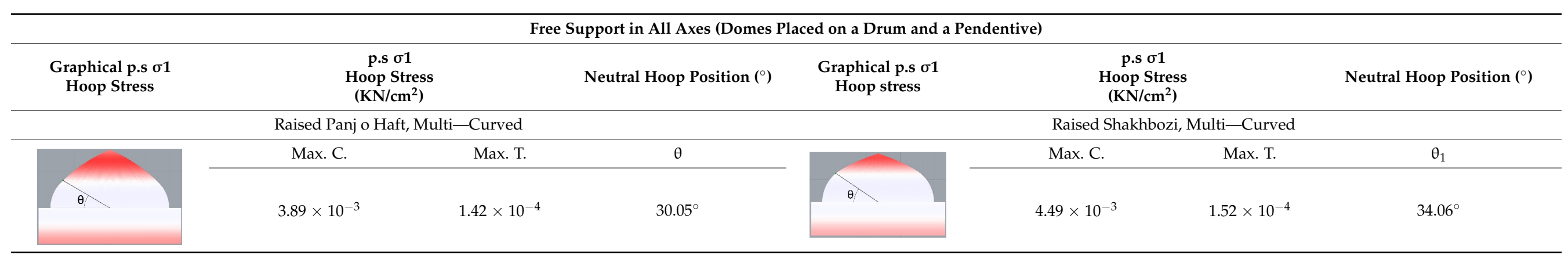

Table 11. Analysis of domes with various thicknesses $-R_{m}=5 \mathrm{~m}, \mathrm{H}_{\text {drum }}=3 \mathrm{~m}, \mathrm{t}_{\text {drum }}=1.1 \times \mathrm{t}_{\text {dome }}, \mathrm{R}_{\text {drum }}=5 \mathrm{~m}, \mathrm{R}_{\mathrm{drum} \text { with pendentive }}=6 \mathrm{~m}$.

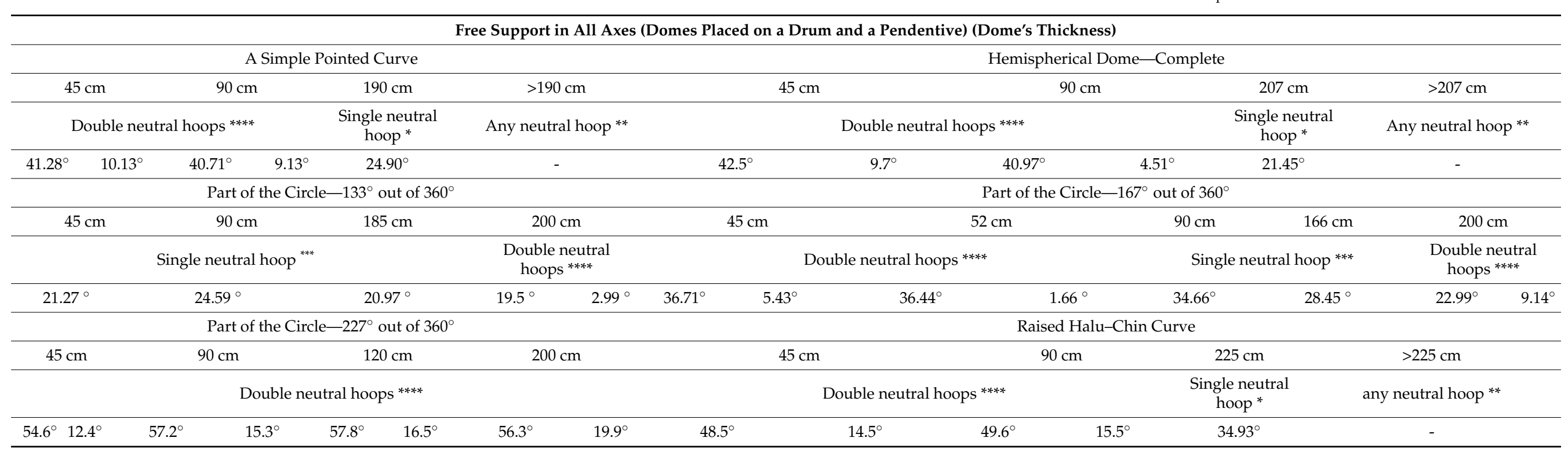


Table 11. Cont.

Free Support in All Axes (Domes Placed on a Drum and a Pendentive) (Dome's Thickness)

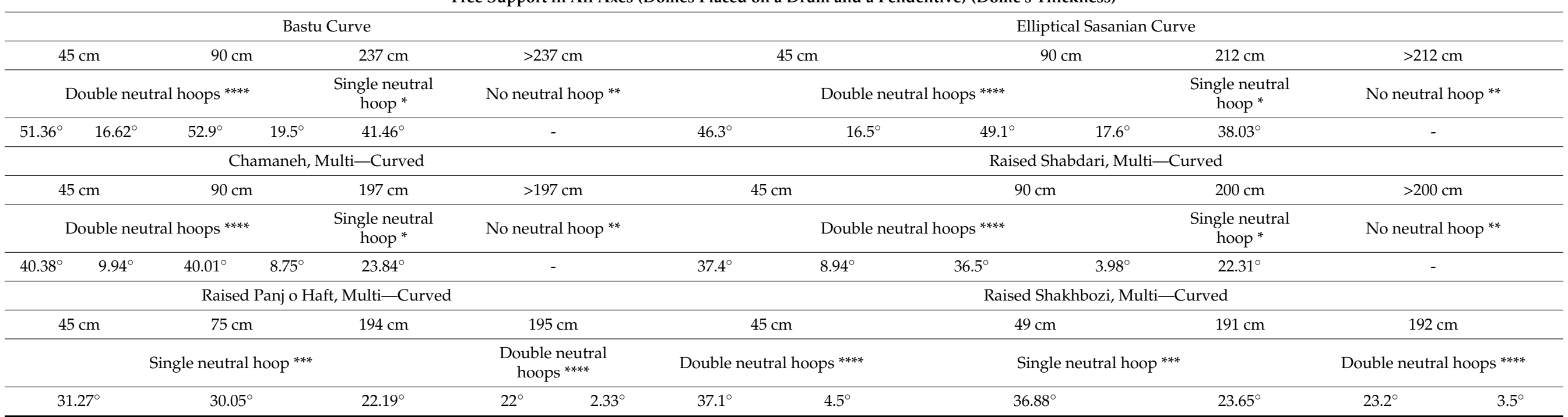

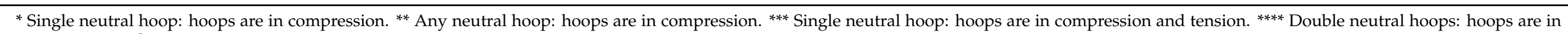
compression and tension. 


\subsubsection{Free Support in X-and Y-Axes}

There is movement restriction in the $X$ - and Y-axes in free support placed on the dome's boundary line. Tables 6 and 7 present free support in the X- and Y-axes with various curvatures and dome thicknesses. Table 6 presents the maximum compression and tension of the hoop stress (p.s o1) and the angle between the neutral hoop(s) and the dome's boundary line.

According to Table 6, the results are as follows:

1. In the dome, its curve is part of the circle $-227^{\circ}$ out of $360^{\circ}$; there is a double neutral hoop. In the others, there is a single neutral hoop;

2. As the height-to-span ratio decreases (the horizontal vector of the thrust line increases), the tension zone decreases.

According to Table 7, the results are as follows:

1. In the dome, its curve is part of the circle $-227^{\circ}$ out of $360^{\circ}$-double neutral hoops for dome's thickness are less than $138 \mathrm{~cm}$, and for more than $138 \mathrm{~cm}$, there is a single neutral hoop. In the others, there is a single neutral hoop;

2. Increasing the dome's thickness makes the tension area larger.

\subsubsection{Free Support in All Axes (Domes Placed on a Drum)}

There is no movement restriction at the junction of the dome and the drum. Tables 8 and 9 present free support in all axes (domes placed on a drum) with variable curvatures and dome thicknesses. Table 8 presents the maximum compression and tension of the hoop stress (p.s o1) and the angle between the neutral hoop(s) and the dome's boundary line.

According to Table 8, the results are as follows:

1. In all curves except the part of the circle-227 $7^{\circ}$ out of $360^{\circ}$ - there is a single neutral hoop;

2. In the dome, its curve is part of the circle $-227^{\circ}$ out of $360^{\circ}$; there are double neutral hoops;

3. As the height-to-span ratio decreases (the horizontal vector of the thrust line increases), the compressive zone increases.

According to Table 9, the curve is part of the circle- $227^{\circ}$ out of $360^{\circ}$ - only in domes, and there are double neutral hoops. In the others, there is a single neutral hoop with compressive and tensile hoops. There is no connection between increasing the dome's thickness and the position of the neutral hoop. This issue can be explained by the interdependent relationship between the thickness of the drum and that of the dome. Whenever the drum's thickness changes, restrictions on the support will change, too.

On the other hand, by increasing the dome's thickness, the dome's reaction to supports will change, and both of them will affect the neutral hoop angle. Therefore, changing all three together bears no linear effect.

\subsubsection{Free Support in All Axes (Domes Placed on a Drum and a Pendentive)}

There is no movement restriction at the junction of the dome and the pendentive. Tables 10 and 11 present free support in all axes (domes placed on a drum and a pendentive) with variable curvatures and dome thicknesses. Table 10 presents the maximum compression and tension of the hoop stress (p.s o1) and the angle between the neutral hoop(s) and the dome's boundary line.

According to Table 10, there is a single neutral hoop in case studies with a lower heightto-span ratio. In the others, there are double neutral hoops, but the ratio is independent of each curve.

According to Table 11, based on the type of curves and dome thickness, the number of neutral hoops is variable.

1. In the dome, its curve is part of the circle- $-133^{\circ}$ out of $360^{\circ}$; for thicknesses less than $185 \mathrm{~cm}$, there is a single neutral hoop, and there are double neutral hoops for thicknesses more than $185 \mathrm{~cm}$; 
2. In the dome, its curve is part of the circle $-167^{\circ}$ out of $360^{\circ}$. For thicknesses less than and equal to $52 \mathrm{~cm}$, there are double neutral hoops; for thicknesses more than 52 and less than $166 \mathrm{~cm}$, there is a single neutral hoop; and for thicknesses more than 166, there is no neutral hoop;

3. In the dome, its curve is part of the circle $-227^{\circ}$ out of $360^{\circ}$; there are double neutral hoops for all thicknesses;

4. In the dome with the raised Panj o haft curve, there is a single neutral hoop for thicknesses less than 195 and double neutral hoops for thicknesses more than $195 \mathrm{~cm}$;

5. In the dome with the raised Shakhbozi curve, there are double neutral hoops for thicknesses less than and equal to $45 \mathrm{~cm}$; a single neutral hoop for thicknesses more than $49 \mathrm{~cm}$ and less than $192 \mathrm{~cm}$; and double neutral hoops for thicknesses more than and equal to $192 \mathrm{~cm}$;

6. In domes other than those mentioned above, there are double neutral hoops for less than a specific thickness, a single neutral hoop for the specific thickness, and no neutral hoop for more than the specific thickness.

\subsection{Diagram of Masonry Domes ( $p . s \sigma 1$ ) Separately Based on a Curve with Constant $90 \mathrm{~cm}$} Thickness and Variable Support

According to Figure 5a-1, the results are correspondingly as follows:

- a. In a hemispherical dome- $180^{\circ}$ of $360^{\circ}$ - the upper neutral hoop is in an almost specific place. The dome's behavior is most different in the lower part, and it is different in the neutral hoop number and tensile stress. The compression stress is almost equal in all supports except the free $X$ and $Y$ support;

- b. The behavior in the part of the circle- $133^{\circ}$ out of $360^{\circ}$-is different from that in the other parts. In fixed support conditions, there is no neutral hoop. However, in other supports, there is one. The p.s $\sigma 1$ is different in different support conditions;

- $\quad$ c. The behavior of the domes shown in Figure 5a,c is similar, except in the fixed support. There is a single neutral hoop in the fixed support with all the compressive hoops;

- d. In the curve with the part of the circle-227 of $360^{\circ}$-before the maximum tensile stress, all types of supports are very similar, except the free support in $\mathrm{X}$ and $\mathrm{Y}$. The lowest maximum tension and compression stress are in the dome with the free support in $X$ and $Y$;

- $\quad$ e. In the dome with the raised Halu-Chin curve, domes with a fixed support and free in all axes (domes placed on a drum and a pendentive) have similar behavior with double neutral hoops. Additionally, the maximum tensile stress is in the free $X$ and Y support;

- $\quad$ f. In the dome with the Bastu curve, its behavior at the top of the upper neutral hoop is similar in all types of support conditions, and the upper neutral hoop is located in almost the same place. The dome's diagrams with fixed support and free in all axes (domes placed on a drum and a pendentive) are the same;

- $\quad$ g. In the dome with an elliptical Sasanian curve, the upper neutral hoop in all types of support is in an almost specific place. The same behavior is observed for the fixed support and free in all axes (domes placed on a drum and a pendentive) support;

- $\quad \mathbf{h}$ and $\mathbf{i}$. The masonry dome behavior in the two figures is similar. The compression region is almost the same in all types of support. There are double neutral hoops in fixed support and free in all axes (domes placed on a drum and a pendentive), and there is a single neutral hoop in the other types of support;

- j. Figure 5j is similar to Figure 5h-i, but there is chaos in the compression region;

- $\quad$ k. In the dome with a raised Panj o haft curve, there is a single neutral hoop in all conditions except the fixed support conditions;

- 1. The behavior of the dome with the raised Shakhbozi Curve is similar to that observed in Figure 5k, though there is some difference in the compression and tension region. 


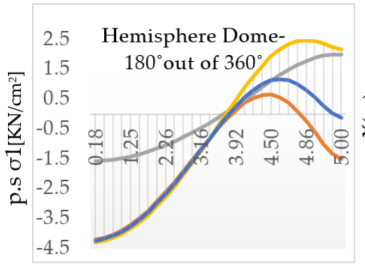

(a)

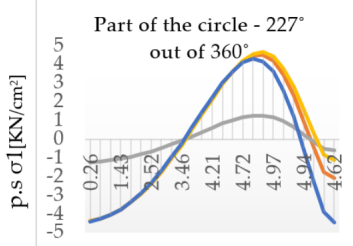

(d)

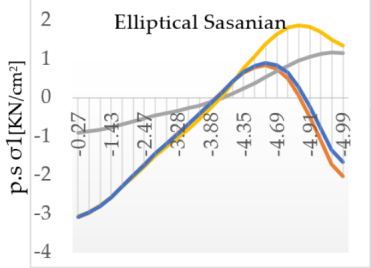

(g)

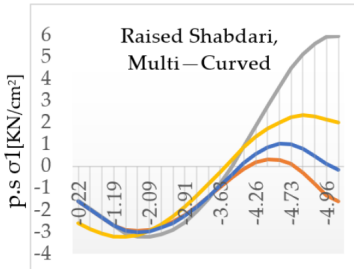

(j)

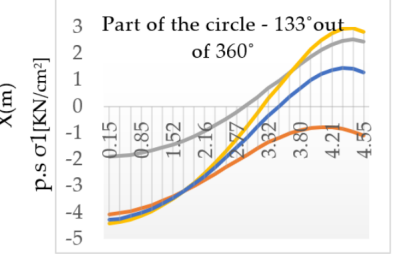

(b)

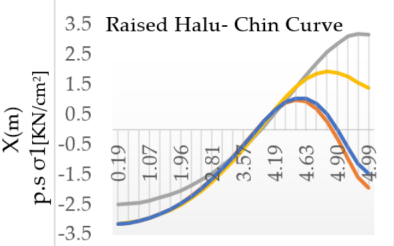

(e)

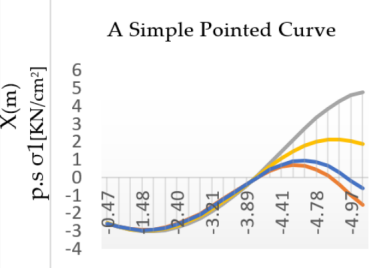

(h)

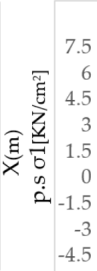

$-4.5$

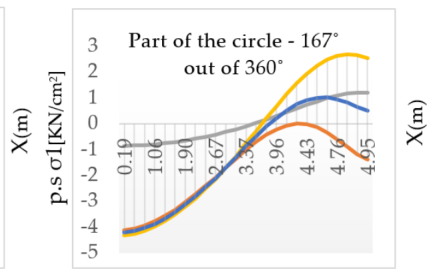

(c)

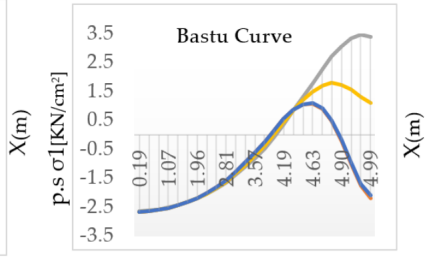

(f)

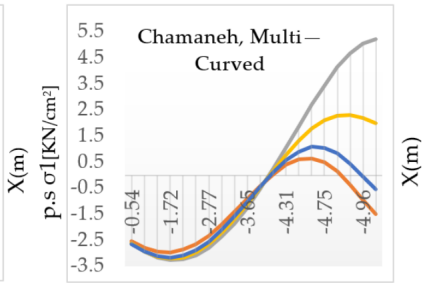

(i)

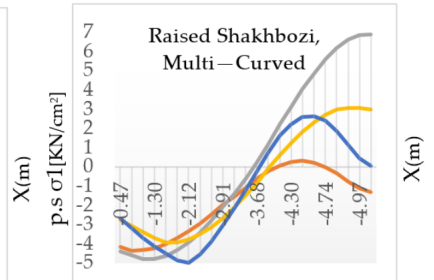

(L)

$$
\begin{aligned}
& \text { - Fixed support } \\
& \text { Free in } \mathrm{X} \text { and } \mathrm{Y} \text { axes } \\
& \text { Free in all axes (Domes place on the drum) } \\
& \text { Free in all axes (Domes place on the drum and the pendentive) }
\end{aligned}
$$

Figure 5. Position of neutral hoops on domes. $R_{m}=5 \mathrm{~m}, \mathrm{t}_{\mathrm{dome}}=90 \mathrm{~cm}, \mathrm{t}_{\mathrm{dome}} / \mathrm{d}_{\mathrm{m}}=0.09, \mathrm{H}_{\mathrm{drum}}=3 \mathrm{~m}$, $t_{\text {drum }}=90 \mathrm{~cm}, R_{\text {drum }}=5 \mathrm{~m}, R_{\text {drum with pendentive }}=6 \mathrm{~m}$. (a) p.s $\sigma 1$ of hemispherical dome $-180^{\circ}$ out of $360^{\circ}$; (b) p.s $\sigma 1$ of part of the circle curve $-133^{\circ}$ out of $360^{\circ}$; (c) p.s $\sigma 1$ of part of the circle curve- $167^{\circ}$ out of $360^{\circ}$; (d) p.s $\sigma 1$ of part of the circle curve $-227^{\circ}$ out of $360^{\circ}$; (e) p.s $\sigma 1$ of raised Halu-Chin curve; (f) p.s $\sigma 1$ of Bastu curve; (g) p.s $\sigma 1$ of Elliptical Sasanian curve; (h) p.s $\sigma 1$ of a simple pointed curve; (i) p.s $\sigma 1$ of Chamaneh, Multi-Curved; (j) p.s $\sigma 1$ of Raised Shabdari, Multi-Curved; (k) p.s $\sigma 1$ of raised Panj o haft, Multi-Curved, (1) p.s $\sigma 1$ of raised Shakhbozi, Multi-Curved.

\subsection{Masonry Dome Behavior}

The masonry dome behavior depends on many factors related to the meridian and hoop forces; unlike the meridian force, the structural behavior of the hoop forces changes at the position of the neutral hoop(s). Neutral hoop(s) are related to the type of support, the dome's curve, and the dome's weight (thickness for domes with the same material). The number of neutral hoops separates four types of the dome's behavior:

1. No neutral hoop, single masonry behavior;

2. Single neutral hoop-all hoops are compressive, double-masonry behavior;

3. Single neutral hoop-hoops are compressive and tensile, double-masonry behavior;

4. Double neutral hoops, treble-masonry dome. 
According to the Eddy and Lévy method, which Stefano Galassi, Giulia Misseri, Luisa Rovero, and Giacomo Tempesta developed, cracks are caused by tensile stress. Eddy's method is explained comprehensively in Section 2.2. Lévy extends Eddy's theory, using the stability of domes with variable thickness to find the exact location of the neutral hoop(s). They propose sliced vaults based on membrane theory in double-masonry dome behavior and assemble the monodimensional elements and the membrane theory approach. In this theory, domes act as separated, sliced vaults in the tension area because of cracks, and the compression area acts as a compressive membrane. They consider the no-tension nature of masonry in their analysis. Figure 6 shows the classification of this method when combined with shell theory.

(a)

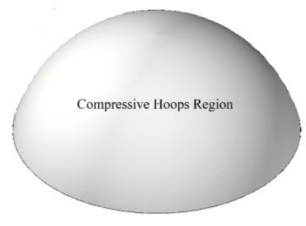

(b)

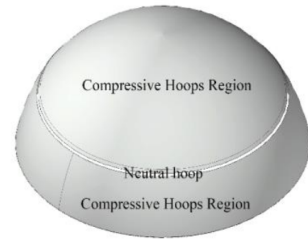

(c)

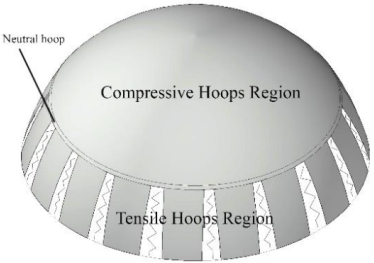

(d)

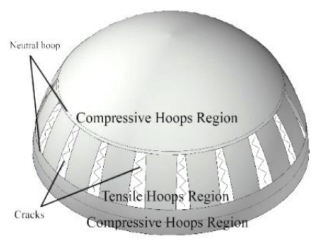

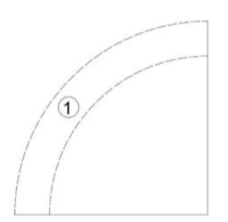
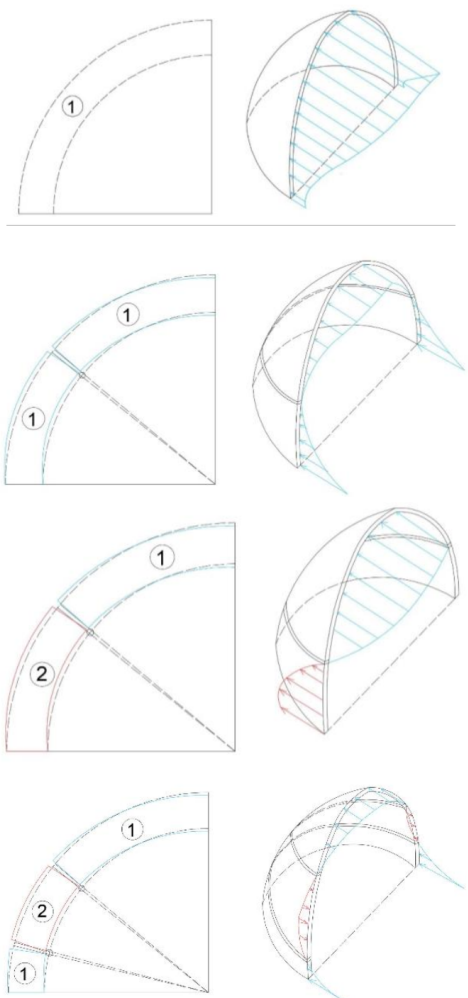

Figure 6. Definition of masonry dome behavior based on the Eddy and Lévy method. (a) Singlemasonry dome; (b) double-masonry dome behavior; (c) double-masonry dome; (d) treble-masonry dome behavior. Region 1 is compressive, and Region 2 is tensile.

In the tension region, domes act as separated, sliced vaults, and the compression region acts as a compressive shell.

In Figure 6a, domes act as a compressive shell for single-masonry dome behavior, and there is no neutral hoop to change masonry dome behavior.

In Figure $6 \mathrm{~b}$, domes act as a compressive shell with two compressive regions for double-masonry dome behavior. A single neutral hoop separates these regions.

In Figure 6c, domes act as a separated, sliced vault in the tensile region for doublemasonry dome behavior and as a compressive shell in the compressive region.

In Figure 6d, domes act as a separated, sliced vault in the tensile region for treblemasonry dome behavior and as a compressive shell in the compressive region.

In general, the final result is presented in Figure 7. 


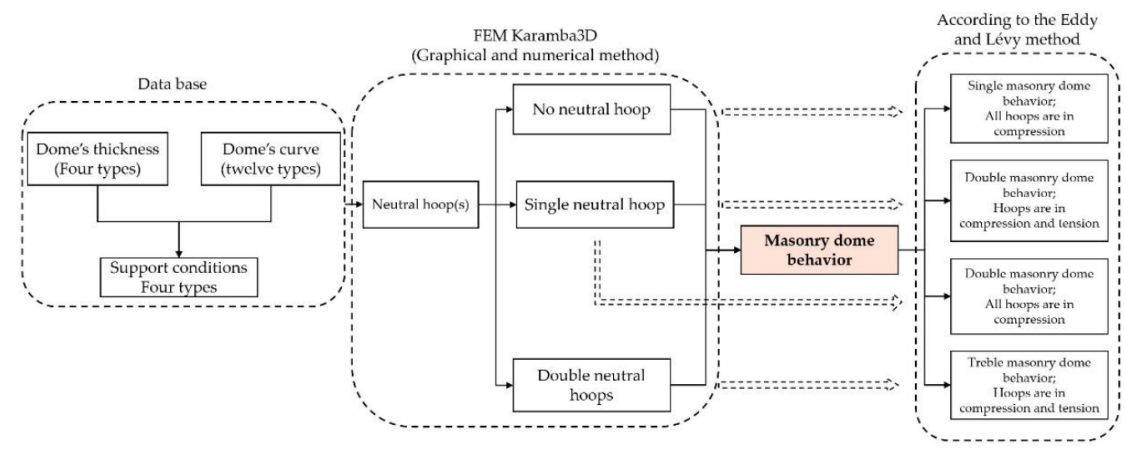

Figure 7. The complete process and results of the research.

\section{Conclusions}

The support is an important part of domes that helps to protect against the gravity loads responsible for transferring vertical and horizontal loads from the dome, but the way in which the force is transferred from the dome to the underlying structure affects masonry domes' behavior. Based on the research conducted in this article, the support conditions can be categorized into four types:

At the fixed support, since it does not allow the dome to move at the support, the reaction force created against the horizontal thrust force creates a second neutral hoop in the dome. However, since the dome's weight also affects the masonry dome's behavior, the fixed support property decreases as its weight (thickness) increases. As a result, it will initially change from double neutral hoops to a single neutral hoop at the specified thickness. Finally, increasing the dome's thickness in the simulation conditions will cause a no-neutral hoop in the masonry dome. Another factor affecting the number of neutral hoops and the masonry dome's behavior is the dome's curve. Whenever the dome's slope decreases at the boundary line, there is no neutral hoop. If the dome's slope sign at the support is the opposite of that of the dome's upper parts, the dome will have two neutral hoops in all cases.

There is a single neutral hoop in the free support in the X-and Y-axes, but in terms of the dome's curve, when the sign of the slope of the supporting part of the dome is different from the upper part of the dome, then there will be double neutral hoops. In this type of support, there is no change in the number of neutral hoops when changing the dome's thickness. The only difference occurs when the dome's support's slope is different from the upper part of the dome. This kind of case study has double neutral hoops at low thicknesses and a single neutral hoop at a certain thickness. For more than this thickness, there is a single neutral hoop.

At the free support in all axes (domes placed on a drum), it is possible to move in three directions because the dome is located on the drums. There is a single neutral hoop for the free support in all axes (domes placed on a drum). Nevertheless, the dome with part of the circle curve- $133^{\circ}$ of $360^{\circ}$ - has double neutral hoops. The same also occurs when the sign of the curve's slope at its support region is different from the sign of the curve's slope at the top of the dome's curve. In this type of support, the number of neutral hoops does not change when the dome's thickness is changed.

In the free support in all axes (domes placed on a drum and a pendentive), there is a single neutral hoop in the dome's curve with a lower height-to-span ratio. This ratio varies in different curves, and it must be analyzed for each dome's curve. In other conditions, the domes have double neutral hoops. Although the type of curve affects the number of neutral hoops, the thickness changes also affect it. The dome has a single neutral hoop at a specific thickness in domes with a high height-to-span ratio. There is no neutral hoop for more than that, and for less than that, there are double neutral hoops.

Nevertheless, in situations where the height-to-span ratio is low and based on the dome's curve, there are two types of behavior. In type 1, it changes from a single neutral hoop at a low thickness to double neutral hoops at a greater thickness. In the second type, 
there is a switching from the state of double neutral hoops in the low thickness to the state of a single neutral hoop and then to the state of double neutral hoops in the dome's greater thickness. However, in domes where the slope sign is different at the beginning and end of the curve, it has double neutral hoops in all thicknesses.

To summarize, with more resistance of support against gravity loads, double neutral hoops are formed. The neutral hoop is also completely influenced by the thickness (weight) and curve of the dome. As the dome's thickness increases, the number of neutral hoops decreases and changes from double neutral hoops to a single one, and finally, the neutral hoop disappears, and all the hoops are compressed. Further, if the slope sign does not change in the dome's curve, it should be analyzed based on the type of support and the dome's thickness for each case study. However, if the slope changes in the dome's curve, double neutral hoops will form. The low ratio of height to the dome's span reduces the tensile zone, but the curve's performance should be considered separately in terms of the number of neutral hoops.

According to the support conditions and the variables of thickness and curve of the dome, there are four types of masonry dome behavior:

1. Single-masonry behavior;

2. Double-masonry behavior, where all hoops are compressive;

3. Double-masonry behavior, where hoops are compressive and tensile;

4. Treble-masonry dome.

In single-masonry behavior, there is no neutral hoop. There is a single neutral hoop in double-masonry behavior (all hoops are compressive/hoops are compressive and tensile). Finally, in the treble-masonry dome, there are double neutral hoops.

Through our research, it has been possible to identify the structural behavior of traditional domes. Therefore, these results can help decide to design, restore, and strengthen masonry domes. Engineers can propose a plan for tensile regions to strengthen there. Additionally, they can optimize their design based on the tensions' path. Additionally, the results of this research have many applications in the repair and restoration of damaged traditional domes.

Author Contributions: Investigation strategy conception, M.B. and A.S.; conceptualization, M.B., A.S. and K.D.; methodology, A.S. and H.S.; investigation, A.S.; data curation, M.B. and K.D.; writingoriginal draft preparation, M.B. and A.S.; writing-review and editing, K.D. and H.S.; visualization and analyzation, A.S.; supervision, M.B., K.D., and H.S.; project administration, M.B. All authors have read and agreed to the published version of the manuscript.

Funding: This research received no external funding.

Institutional Review Board Statement: Not applicable.

Informed Consent Statement: Not applicable.

Data Availability Statement: The data presented in this study are available on request from the corresponding author.

Acknowledgments: A. Sh. would like to express his deep and sincere gratitude to Peter Bauer, Vienna Technical University professor. He and his architectural science laboratory provided A. Sh. with a good atmosphere and facilities when A. Sh. was a visiting scholar. They provided him with a Karamba3D license and tutorials to carry out his project in his Ph.D. thesis sections.

Conflicts of Interest: The authors declare no conflict of interest.

\section{References}

1. Melaragno, M. An Introduction to Shell Structures: The Art and Science of Vaulting; Van Nostrand Reinhold: New York, NY, USA, $1991 ;$ p. 4.

2. Lagomarsino, S.; Podestà, S. Seismic Vulnerability of Ancient Churches: I. Damage Assessment and Emergency Planning. Earthquake Spectra 2004, 20, 377-394. [CrossRef]

3. Fuentes, D.D.; Baquedano Julià, P.A.; D'Amato, M.; Laterza, M. Preliminary seismic damage assessment of Mexican churches after September 2017 earthquakes. Int. J. Archi. Herit. 2019, 1-21. [CrossRef] 
4. Galassi, S.; Misseri, G.; Rovero, L.; Tempesta, G. Equilibrium analysis of masonry domes, on the analytical interpretation of the Eddy-Lévy graphical method. Int. J. Archit. Herit. 2017, 11, 1-34. [CrossRef]

5. Heyman, J. The Stone Skeleton; Cambridge University Press: Cambridge, UK, 1995.

6. Como, M. Statics of Historic Masonry Constructions; Springer: Berlin, Germany, 2017; pp. 195-297.

7. Eliassen, M.; Huseby, A. The Digital Workflow of Parametric Structural Design, Developing Grid Shells in a Nordic Climate. Master's Thesis, Norwegian University of Science and Technology, Trondheim, Norway, 2018; p. 15.

8. Karamba3D. Available online: https:/ / www.karamba3d.com (accessed on 29 November 2020).

9. Dzwierzynska, J.; Prokopska, A. Pre-rationalized parametric designing of roof shells formed by repetitive modules of Catalan surfaces. Civ. Eng. Sym. 2018, 10, 105. [CrossRef]

10. Preisinger, C.; Heimrath, M. Karamba-a toolkit for parametric structural design. Struct. Eng. Inter. 2020, 24, 217-221. [CrossRef]

11. Andrea, P. The Four Books of Architecture; Dover Publications: Milan, Italy, 1965.

12. Vincenzo, S. L'idea Dell'architettura Universale; Coi tipi di Borroni e Scotti: Milan, Italy, 1838.

13. Santiago, H. The analysis of masonry architecture: A historical approach. Archit. Sci. Revi. 2008, 51, $297-328$.

14. Robert, H. A Description of Helioscopes, and Some Other Instruments; T.R.: London, UK, 1675.

15. Jacques, H. Structural Analysis: A Historical Approach; Cambridge University Press: Cambridge, UK, 1998.

16. Dermot, O. Funicular analysis of masonry vaults. Comput. Struct. 1999, 73, 187-197.

17. Block, P.; DeJong, M.; Ochsendorf, J. As Hangs the Flexible Line: Equilibrium of Masonry Arches. Nexus Net. J. 2006, 8, 13-24. [CrossRef]

18. Lau, W.W. Equilibrium Analysis of Masonry Domes. Master's Thesis, Massachusetts Institute of Technology, Cambridge, MA, USA, 2006.

19. Schodek. D., L. Structures, Fourth Illustrated; Prentice Hall: Hoboken, NJ, USA, 2001.

20. Xie, Y.M.; Felicetti, P.; Tang, J.W. Form finding for complex structures using evolutionary structural optimization method. Desi. Stud. 2005, 26, 55-72. [CrossRef]

21. Makris, N.; Alexakis, H. From Hooke's “Hanging Chain" and Milankovitch's "Druckkurven" to a variational formulation: The adventure of the thrust-line of masonry arches. In 10th HSTAM International Congress on Mechanics; Technical University of Crete: Chania, Greece, 2013.

22. Tempesta, G.; Paradiso, M.; Galassi, S.; Pieroni, E. Maurice Lévy's original contribution to the analysis of masonry domes. Domes Cupolas J. 2015, 2, 85-91.

23. Bouguer, P. Sur les lignes courbes qui sont propres à former les voûtes en dôme. Mém. Acadé. Roy. Sci. 1734, 149-166.

24. Benvenuto, E. Chapter I: Statics and Resistance of Solids. Chapter II: Vaulted Structures and Elastic Systems. In An Introduction to the History of Structural Mechanics; Springer-Verlag: New York, NY, USA, 1991.

25. Bossut, C. Nouvelles Recherches sur L'équilibre des Voûtes en Dôme, Mémoires; Académie: Paris, France, 1778.

26. Coulomb, C.A. Essai sur une Application des Règles de Maximis et Minimis à Quelques Problèmes de Statique, Relatifs a L'architecture; De l'Imprimerie Royale: Paris, France, 1776.

27. Mascheroni, L. Nuove Ricerche Sull'equilibrio Delle Volte; Per Francesco Locatelli: Bergamo, Italy, 1785.

28. Salimbeni, L. Degli Archi e Delle Volte Libri Sei; Dionigi Ramanzini: Verona, Italy, 1787.

29. Poleni, G.; Arroyo, S.P. Memorie Istoriche Della Gran Cupola del Tempio Vaticano; INTEMAC: Padova, Italy, 1748.

30. Navier, C. Résumé des le Leçons Données a l'École des Ponts et Chaussées sur L'application de la Mécanique a L'établissement des Constructions et des Machines; Didot: Paris, Italy, 1826.

31. Navier, C. Résumé des Leçons Données a l'École des Ponts et Chaussées sur L'application de la Mécanique a L'établissement des Constructions et des Machines; Chez Carilian-Goeury: Paris, Italy, 1833.

32. Heyman, J. The Masonry Arch; Ellis Horwood Limited: West Sussex, UK, 1982; p. 24.

33. Prager, W. An Introduction to Plasticity; Addison-Wesley Publishing Company: Boston, MA, USA, 1959.

34. Geckeler, J.W. Elastostatik. Mech. Elastis. Körper. 1928, 6, 141-308.

35. Truesdell, C. The Membrane Theory of Shells of Revolution. Trans. Amer. Math. Soc. 1945, 58, 96-166. [CrossRef]

36. Schwedler, J.W. Theorie der Stützlinie. Ein Beitrag zur Form und Stärke gewölbter Bögen. Z. für Bauwes. 1859, 9, $109-126$.

37. Beltrami, E. Sull'equililibrio delle superfici flessibili ed inestensibili. Mem. dell'Accademia delle Sci. dell'Istituto di Bologna 1882, 3, 217-265.

38. Wolfe, W.S. Graphical Analysis: A Textbook on Graphic Statics; McGraw-Hill Book Co: New York, NY, USA, $1921 ;$ pp. $250-253$.

39. Billington, D.P. Thin Shell Concrete Structures; McGraw-Hill Book Co.: New York, NY, USA, 1982.

40. Eddy, H.T. New Constructions in Graphical Statics; D. Van Nostrand: New York, NY, USA, 1877; pp. 56-57.

41. Eddy, H.T. Chapter XVI, Researches in Graphical Statics. In Spherical Dome of Masonry; Van Nostrand's. Royale des Sciences: New York, NY, USA, 1878; pp. 587-596.

42. Cavalagli, N.; Gusella, V. Structural Investigation of 18th-Century Ogival Masonry Domes: From Carlo Fontana to Bernardo Vittone. Inter. J. Archit. Herit. 2015, 9, 265-276. [CrossRef]

43. Heyman, J. On shell solutions for masonry domes. Intern. J. Solids Struct. 1967, 3, 227-241. [CrossRef]

44. Ventsel, E.; Krauthammer, T. Thin Plates and Shells: Theory, Analysis, and Applications, Applied. Mech. Rev. 2002, 55, B72-B73. [CrossRef]

45. Blaauwendraad, J.; Hoefakker, J.H. Structural Shell Analysis, Understanding and Application; Springer: London, UK, 2014. 
46. Farshad, M. On the shape of momentless tensionless masonry domes. Build. Environ. 1992, 12, 81-85. [CrossRef]

47. Farshad, M. Design and Analysis of Shell Structures; Kluwer Academic Publishers: Dordrecht, The Netherlands, 1992.

48. Robison, E.C. Peter's Dome: The Michelangelo and Della Porta designs. In Domes from Antiquity to Present: Proceedings of the IASS, MSU International Symposium; Mimar Sinan University Istanbul: Istanbul, Turkey, 1988.

49. Mercan, B.; Stolarski, H.K.; Schultz, A.E. Arc-length and explicit methods for static analysis of prestressed concrete members. Comput. Concr. 2016, 18, 17-37. [CrossRef]

50. Fafard, M.; Maassicotte, B. Geometrical interpretation of the arc-length method. Comput. Struct. 1993, 46, 603-615. [CrossRef]

51. Lucchesi, M.; Padovani, C.; Zani, N. Masonry-like solids with bounded compressive strength. Intern. J. Solids Struct. 1995, 33, 1961-1994. [CrossRef]

52. Metwally, M.I. Design of Transfer Slabs Using Strut-and-Tie Model. Master's Thesis, Mansoura University, Mansoura, Egypt, 2016.

53. Yang, X.-S. Engineering Mathematics with Examples and Applications; Academic Press: London, UK, 2017 ; pp. $231-241$.

54. Preisinger, C. Linking Structure and Parametric Geometry. Archit. Design. 2013, 83, 110-113. [CrossRef]

55. MIT Masonry Group. Available online: http://web.mit.edu/masonry (accessed on 22 October 2020).

56. Pauletta, M.; Luca, D.D.; Russo, E.; Fumo, C. Seismic rehabilitation of cultural heritage masonry buildings with unbounded fiber-reinforced elastomeric isolators (U-FREIs). J. Cult. Herit. 2018, 32, 84-97. [CrossRef]

57. Sacco, E. A nonlinear homogenization procedure for periodic masonry. Euro. J. Mech. A Solids. 2009, 28, 209-222. [CrossRef]

58. Pantò, B.; Cannizzaro, F.; Caddemi, S.; Caliò, I.; Chácara, C.; Lourenço, P.B. Nonlinear Modelling of Curved Masonry Structures after Seismic Retrofit through FRP Reinforcing. Buildings 2017, 7, 79. [CrossRef]

59. Hejazi, M.; Ghamari, M.; Beheshti, H. Parametric Study of Failure Load of Persian Brick Masonry Domes Stiffened by FRP Strips under Concentrated Monotonic Loads. Ferdowsi. Civil Engin. J. 2016, 28, $29-48$.

60. Hejazi, M.; Pourabedin, M. Performance of Persian brick masonry discontinuous double-shell domes against earthquakes. Engin. Fail. Analysis. 2021, 199, 1-23. [CrossRef]

61. Binda, L.; Fontana, A.; Frigerio, G. Mechanical Behaviour of Brick Masonries Derived From unit and Mortar Characteristics. In Proceedings of the 8th International Brick and Block Masonry Conference, Dublin, Ireland, 19-21 September 1988; Elsevier Applied Science: London, UK, 1988.

62. Hejazi, M.; Baranizade, S.; Daii, M. Optimal shape, breaking load and buckling load of historical Iranian brick domes. Hous. Rural Environ. J. 2016, 155, 61-76. 